\title{
Effect of $\alpha-\alpha^{\prime}$ phase separation on notch impact behavior of oxide dispersion strengthened (ODS) Fe20Cr5Al alloy
}

\author{
J. Chao $^{1}$, C. Capdevila ${ }^{1}$, M. Serrano ${ }^{2}$, A. Garcia-Junceda ${ }^{2}$, J.A. Jimenez ${ }^{1}$, and M. K. Miller ${ }^{3}$ \\ ${ }^{1}$ Departament of Physical Metallurgy, Centro Nacional de Investigaciones Metalúrgicas (CENIM-CSIC), Avda. \\ Gregorio del Amo 8, 28040 Madrid, Spain \\ ${ }^{2}$ División de Materiales Estructurales, Centro Investigaciones Medioambientales y tecnológicas (CIEMAT), \\ Avda. Complutense 22, 28040 Madrid, Spain \\ ${ }^{3}$ Materials Science and Technology Division, Oak Ridge National Laboratory, PO Box 2008, Oak Ridge, TN \\ 37831-6139, USA
}

\begin{abstract}
The effects of Fe-rich $(\alpha)$ and $\mathrm{Cr}$-enriched $\left(\alpha^{\prime}\right)$ phase separation, occurring during ageing at $475{ }^{\circ} \mathrm{C}$ on the microstructure and mechanical properties of Fe-20Cr-6Al ODS alloy (PM2000 ${ }^{\mathrm{TM}}$ ) hot-rolled tube, were investigated by means of atom probe tomography, microhardness, tensile and V-notched Charpy impact tests. Disregarding of the aging treatment, this material presents splitting of crack-divider type in longitudinal-transverse (LT) specimens, whereas crack-arrester type is observed in longitudinal- short transverse (LS) specimens, which induces significant differences in ductile-to-brittle transition temperature (DBTT) and upper shelf energy (USE). Additionally, a significant increase in DBTT and decrease in USE were recorded during ageing at $475{ }^{\circ} \mathrm{C}$ as a function of aging time. The main cause of embrittlement is the $\alpha-\alpha^{\prime}$
\end{abstract}

\footnotetext{
- Corresponding author:
}

Email: ccm@cenim.csic.es; Telf: +34 915538900;Fax: +34 5347425 
phase separation with an apparent activation energy measured in the range of $214-240 \mathrm{~kJ} / \mathrm{mol}$, which is consistent with the activation energy for $\mathrm{Cr}$ diffusion in this type of alloy.

Keywords: toughness, phase separation, mechanical alloying, tomography, oxide dispersion strengthened ferritic alloys

\section{Introduction}

Oxide dispersion strengthened (ODS) steels produced by mechanical milling and hot isostatic pressing (HIP) are considered potential structural materials for future fusion reactors. Dispersion strengthening appears to be the most promising approach to widening the operating temperature window of the actual ferritic steels [1-2]. The requirements for fusion reactors, sodium fast reactors (SFR), very-high temperature reactors (VHTR), super critical water reactors (SCWR), or other GEN IV nuclear energy systems are different, but generic development can be considered for these materials. Due to their high creep rupture strength and excellent swelling resistance, ODS ferritic materials can be used in several types of reactors. This diversity of uses has resulted in many developments for these alloys. [-4]

One of the common key issues for the use of ODS ferritic steels as structural materials for advanced fission and fusion nuclear systems, is to improve its fracture toughness, as it is lower than conventional ferritic steels. [5] As described previously, the non-hardening embrittlement of Fe-20Cr-6Al ODS alloys reinforced with 0.5 wt.\% of $\mathrm{Y}_{2} \mathrm{O}_{3}$ particles (designated as $\mathrm{PM} 2000^{\mathrm{TM}}$ ) manifests itself by a decrease in toughness without an increase in strength [6-8]. This embrittlement is associated generally with intergranular failure that arises from the grain boundary segregation and precipitation of arrays of coarse Ytrium-Aluminum garnets (YAGs) along the extrusion direction and the consequent loss of grain boundary cohesion [9 10-11]. These arrays of oxides shift the ductile-to-brittle transition temperature (DBTT) to higher temperatures and play an important role in the non-hardening embrittlement. However, the experimental results reported in this paper lead us to conclude that the morphology of brittle features in the ODS ferritic steels depends on 
multiple factors, which not only include the oxide morphology and distribution, but also microstructural factors, such as microtexture, effective grain size, and plastic anisotropy.

It is also well known that $\mathrm{Fe}-\mathrm{Cr}$ ferritic alloys face a severe embrittlement problem because their service temperature lies in the range of $300-500^{\circ} \mathrm{C}$, where phase separation into Fe-rich $(\alpha)$ and $\mathrm{Cr}$-enriched $\left(\alpha^{\prime}\right)$ phases occurs. For this reason, $\mathrm{Fe}-\mathrm{Cr}$ steels are at the centre of a large amount of basic research, both experimental and numerical [12-13]. In this paper, the hardening and the notch impact behaviours are correlated with an atom probe tomography microstructural characterization of a PM $2000^{\mathrm{TM}}$ alloy that was annealed at $475^{\circ} \mathrm{C}$.

\section{Materials and Experimental Techniques}

PM $2000^{\mathrm{TM}}$ is a dispersion-strengthened steel manufactured by a mechanical alloying (MA) process by Plansee $\mathrm{GmbH}$ in the form of hot-rolled tubes, as described elsewhere [14].The chemical composition of the PM $2000^{\mathrm{TM}}$ alloy used in this study, as determined by X-ray Fluorescence (XRF), is given in Table 1.

Microtexture analysis of the as-hot rolled PM $2000^{\mathrm{TM}}$ tube specimens was performed by the Electron Backscattering Diffraction (EBSD) imaging technique in a scanning electron microscope (SEM). EBSD patterns were collected at various locations on flat sections that were mechanically polished with colloidal silica (50 nm particle size) in the final stage. Ultrasonic cleaning in ethanol at $30^{\circ} \mathrm{C}$ is performed to remove all impurities from the previous steps. The EBSD patterns were generated at an acceleration voltage of 20 keV and collected using a of Oxford Instruments CRYSTAL detector mounted in a JEOL model JSM6300. Indexing of the Kikuchi lines and the determination of the orientations were performed with CHANNEL 5 software developed by HKL Technology. The results were represented in the form of inverse pole figure (IPF) maps, which give the orientation of a macroscopic direction with respect to a specific crystal direction. 
Atom probe tomography (APT) specimens were cut from the bulk material and electropolished with the standard double layer and micropolishing methods. For some specimens, a focused ion beam (FIB) technique was used in the final stage of the specimen preparation. APT was performed in the Oak Ridge National Laboratory's (ORNL) local electrode atom probe (LEAP ${ }^{\circledR} 4000 \mathrm{X}$ HR) manufactured by Cameca Instruments. The LEAP $^{\circledR}$ was operated with a specimen temperature of $60 \mathrm{~K}$, a pulse repetition rate of 200 $\mathrm{kHz}$, and a pulse fraction of 0.2. Only data sets with more than 2.5 million atoms were used to ensure that the reconstructed volume of material is sufficient to characterize the phase separation. The treatment of the data is performed using standard tools for APT characterization [15-16].

The tensile specimens, fabricated parallel to the rolling direction (RD) of the tube, had a gauge length of 22 $\mathrm{mm}$ and a diameter of $3 \mathrm{~mm}$. The samples were tested at room temperature at a strain rate of $10^{-4} \mathrm{~s}^{-1}$. The $0.2 \%$ yield strength (YS), the ultimate tensile strength (UTS), uniform $\left(\varepsilon_{u}\right)$ and total $\left(\varepsilon_{t}\right)$ elongation, were evaluated from the stress/strain curves. A Class B1 extensometer with a gage length of $20 \mathrm{~mm}$ was used to measure the elongation.

The orientation of the impact specimens are designated following ASTM:399 standard by two letters. The first letter designates the direction normal to the crack plane and the second letter designates the direction parallel to the striking direction, i.e., L (longitudinal) direction is parallel to RD (rolling direction), T (transverse) is parallel to TD (transverse direction), and S (short transverse) direction is parallel to ND (normal direction). Charpy specimens of $55 \times 6.2 \times 6.2 \mathrm{~mm}^{3}$ with a $1.25 \mathrm{~mm}$ deep V-notch were fabricated in the LT and LS orientations. These reduced-section Charpy specimens were subjected to an impact energy of $147 \mathrm{~J}$ and a velocity at the contact instant of $5.4 \mathrm{~m} \mathrm{~s}^{-1}$ in a temperature range between $-196{ }^{\circ} \mathrm{C}$ and 425 ${ }^{\circ} \mathrm{C}$. The DBTT was determined for impact energy equal to one-half of the difference between the respective lower and upper shelf (USE) energies. For LT specimens, the DBTT for 0,5 , and $500 \mathrm{~h}$ aging treatments was of 0,30 and $110^{\circ} \mathrm{C}$, respectively, whereas for $L S$ specimens they were $-10,0$, and $180^{\circ} \mathrm{C}$, respectively. 


\section{Results and discussion}

\subsection{Microstructure of as-rolled samples}

The microstructures after hot-rolling in the LT and TS planes are shown in Figure 1(a) and (b), respectively. The microstructure consists of $20 \mu \mathrm{m}$ grains of ferrite elongated in RD, with a fine, almost equiaxed, section of grain sizes $\sim 0.5 \mu \mathrm{m}$ in the TS plane. As described elsewhere [17], the ODS particle reinforcement, i.e., complex Y-Al oxides, with sizes ranging from $3-40 \mathrm{~nm}$ are preferentially located at the ferrite grain boundaries. Besides these oxide particles, numerous large inclusions with complex compositions were found throughout the sample, which preferentially form large stringers in LS plane. The investigations showed those stringers are formed by large $\gamma-\mathrm{Al}_{2} \mathrm{O}_{3}$ inclusions as well as complex $\gamma-\mathrm{Al}_{2} \mathrm{O}_{3} / \mathrm{Y}-\mathrm{Al}-\mathrm{O}$ impurities, which may additionally enclose smaller Ti(C,N) particles [17].

EBSD analyses were performed to determine the microtexture in the LT, TS, and LS planes. The IPF maps obtained are shown in Figure 1(c), which indicate the $\langle\mathrm{UVW}>$ directions that are parallel to the Z-direction of the sample reference system. Texture analyses reveal that more than $80 \%$ of indexed grains present the $<110>$ direction parallel to the RD, i.e., there is a major presence of (110) planes in the TS. No $\{100\}$ cleavage planes were detected in the TS plane. This texture is typical of body centered cubic materials deformed by either extrusion or rolling. It is clear from Figure 1 (c) that ND $\|<100>$, i.e., the (100) plane is parallel to the sheet tube surface. Likewise, this figure also indicates that the $R D \|<110>$ and the RD plane not only contain the $<110\rangle$ direction, but also the $<111>$. Therefore, it could be concluded that the asreceived microstructure presents a strong texture with $\mathrm{RD} \|<110>$ and ND ||$<100\rangle$. 
3.1.1 The $\alpha$ - $\alpha^{\prime}$ phase separation in PM 2000TM: As described in previous work [18 192021 -22], phase separation within the low-temperature miscibility gap occurs in the PM 2000TM alloy during isothermal annealing at $475{ }^{\circ} \mathrm{C}$ to form Fe-rich $\alpha$ and $\mathrm{Cr}$-enriched $\alpha^{\prime}$ phases. The evolution of the fine scale microstructure has been reported elsewhere $[19,23]$. The three-dimensional microstructure, as determined by APT, resulting from phase separation at $475^{\circ} \mathrm{C}$ for $500 \mathrm{~h}$ is shown in Figure 2(a). At this temperature and for the relatively low chromium content of the alloy, the $\alpha^{\prime}$ phase is in the form of isolated particles rather than the interconnected network structure observed previously for higher chromium (30-45\% Cr) alloys [24].

The kinetics of phase separation was quantitatively determined by analyzing the evolution of the geometrical domain size $(\lambda)$ and the composition amplitude $\left(\Delta C_{c r}\right)$. The composition amplitude was determined from proximity histograms [25] and the scale from the 3D autocorrelation function [26]. The change in the compositions of the $\alpha$ and $\alpha^{\prime}$ phase with annealing time at $475^{\circ} \mathrm{C}$ are listed in Table 2 . The values of $\lambda$ ( $\alpha^{\prime}$ sizes) measured from the first maximum of the autocorrelation function for the different aging conditions are summarized in Table 3. Both the size and $\mathrm{Cr}$ content of the $\alpha^{\prime}$ phase increase with aging time. The evolution of $\Delta \mathrm{C}_{\mathrm{cr}}$ and $\lambda$ with aging time, t, at $475{ }^{\circ} \mathrm{C}$ is shown in Figure $2(\mathrm{~b})$ and (c), respectively. The evolution with time of $\lambda$ can be fitted to a power law with an exponent value of 0.28 $\left(R^{2}=0.93\right)$, which is consistent with the power law growth of the mean precipitate size $R(t)$ varying as $\sim t^{1 / 3}$ predicted by the Lifshitz-Slyozov-Wagner (LSW) theory [27 -28]. It can be concluded from the APT analysis of ageing PM $2000^{\mathrm{TM}}$ at $475^{\circ} \mathrm{C}$ is that the formation of nanometer sized particles (average value of $\lambda$ after $500 \mathrm{~h}$ is $4.8 \mathrm{~nm}$ ) takes place.

The $\alpha-\alpha^{\prime}$ phase separation in PM $2000^{\mathrm{TM}}$ leads to a hardness increase that results from the interaction of dislocations with the internal stresses and composition gradients of the two-phase mixture [29]. As the hardening is thermally activated, the apparent activation energy is measured assuming an Austin-Rickett (AR) type equation. The AR equation is a phenomenological equation that has been used successfully to 
predict the nitride precipitation process in a Fe-2 at. \% Al system [30]. In the AR equation, the transformed fraction $f(t)$ as a function of time $t$ is written as

$$
\frac{\mathrm{f}(\mathrm{t})}{1-\mathrm{f}(\mathrm{t})}=\mathrm{k}(\mathrm{T}) \mathrm{t}^{\mathrm{n}}
$$

The fraction precipitated $\mathrm{f}(\mathrm{t})$ can be related with the microhardness $(\mathrm{HV})$ values by defining the ratio:

$$
\mathrm{Y}=\frac{\mathrm{HV}-\mathrm{HV}_{0}}{\mathrm{HV}_{\max }-\mathrm{HV}_{0}}
$$

The activation energy, determined from microhardness data, Figure 3 , is in the range of $214-240 \mathrm{~kJ} / \mathrm{mol}$. This energy is similar to the diffusion activation energy of $\mathrm{Cr}(203 \mathrm{~kJ} / \mathrm{mol})$ and $\mathrm{Fe}(211 \mathrm{~kJ} / \mathrm{mol})$ in $\mathrm{Fe}-26 \mathrm{Cr}$ steel [31]. Therefore, the formation of the $\mathrm{Cr}$-enriched $\alpha^{\prime}$ phase is related to the diffusion of $\mathrm{Cr}$ and/or Fe in the ferrite matrix. These results are consistent with APT results which conclude that the $\alpha-\alpha^{\prime}$ phase separation in $\mathrm{PM} 2000^{\mathrm{TM}}$ is similar to that observed in $\mathrm{Fe}-\mathrm{Cr}$ and many $\mathrm{Fe}-\mathrm{Cr}-\mathrm{X}$ systems, where the diffusion activation energy of $\mathrm{Cr}$ within the miscibility gap will not be significantly affected by the $\mathrm{Cr}$ content in the high-Cr ferritic ODS steel matrix. The $\mathrm{Cr}$ content will control the total amount of $\alpha^{\prime}$ phase formed from the lever rule. More detailed analysis carried of the phase separation process in Fe-Cr-Al by APT [19] revealed a progressive depletion of $\mathrm{Al}$ from the $\mathrm{Cr}$-rich $\alpha^{\prime}$ phase during isothermal aging at $475^{\circ} \mathrm{C}$ for times between 10 and $3,600 \mathrm{~h}$.

\subsection{Tensile properties}

The evolution of strength (YS and UTS), and elongation $\left(\varepsilon_{\mathrm{u}}\right.$ and $\left.\varepsilon_{\mathrm{t}}\right)$ with ageing time at $475{ }^{\circ} \mathrm{C}$ for different testing temperatures ranging from $-60{ }^{\circ} \mathrm{C}$ to $300{ }^{\circ} \mathrm{C}$ are shown in Figure $4(\mathrm{a})$ and (b), respectively. In the unaged samples, the difference of $\sim 150 \mathrm{MPa}$ between the YS and TS are similar with increasing test temperature, although slightly larger differences are observed ( 200 MPa) for test temperatures of 150 
and $300{ }^{\circ} \mathrm{C}$. This result indicates a substantial work-hardening in the range of temperatures tested, with a tendency to increase as the test temperature is increased. The total elongation at fracture decreases as temperature increases in the temperature range between $-60^{\circ} \mathrm{C}$ and $150^{\circ} \mathrm{C}$. At temperatures between 150 and $300{ }^{\circ} \mathrm{C}$ the value of $\varepsilon_{\mathrm{t}}$ is constant. No substantial differences in the uniform elongation are observed with the testing temperature in the range of temperatures analyzed.

The aging treatment at $475{ }^{\circ} \mathrm{C}$ causes a significant increase in both YS and UTS, with a concomitant decrease in both $\varepsilon_{\mathrm{u}}$ and $\varepsilon_{\mathrm{t}}$. The difference between YS and UTS is reduced with increasing ageing time. Moreover, whereas a continuous decrease of the YS and UTS with testing temperature occurs, the reduction in area can be considered constant for test temperatures above $100{ }^{\circ} \mathrm{C}$.

The effect of ageing time at $475{ }^{\circ} \mathrm{C}$ on stress-strain behavior for room temperature tests is presented in Figure 5(a). The increase in YS is not a steady state process. Almost $67 \%$ of the increase in the yield strength is achieved within the first $100 \mathrm{~h}$ of aging. Although this increase in YS is not saturated after $520 \mathrm{~h}$, the increment between 330 and $520 \mathrm{~h}$ is reduced to $12 \%$ of the total increment in YS. The evolution of the increment of yield strength ( $\Delta \mathrm{YS})$ with $\Delta \mathrm{C}_{\mathrm{cr}}$ is shown in Figure $5(\mathrm{~b})$. The strength increases almost proportionally with the amplitude of the $\mathrm{Cr}$ concentration in the $\alpha^{\prime}$ phase, which indicates that the strengthening mechanism is closely related to the $\alpha-\alpha^{\prime}$ phase separation process. The effect of the phase separation process on strengthening is twofold: firstly, the $\alpha-\alpha^{\prime}$ phase separation induces a stress field (misfit between the $\alpha$ and $\alpha^{\prime}$ phases) that hinders dislocations from propagating, as described by Cahn [32]. Cahn also reported that a dislocation in a phase-separated structure experiences a force from the internal stresses due to periodic variations of the lattice parameter. Secondly, the spatial variation in the Young's modulus associated with the composition modulation is also considered as an obstacle for the motion of dislocations. Previous work on the strain hardening of Fe-30\% $\mathrm{Cr}$ alloy [33] showed that the above two factors contribute to the major fraction of the $\Delta \mathrm{YS}$ and constitute the athermal component of the $\Delta \mathrm{YS}$ [33]. 
It was also proposed that the thermal component of the $\Delta \mathrm{YS}$ can be attributed to the increase of the retarding force of $\mathrm{Fe}-\mathrm{Cr}$ bonds on the dislocation movement relative to those of $\mathrm{Fe}-\mathrm{Fe}$ and $\mathrm{Cr}$ - $\mathrm{Cr}$ bonds [33].

The macroscopic appearance of the fracture surfaces, Figure 6, indicates a significant area reduction and a fracture appearance that depends on test temperature and aging time. At high temperatures $\left(300{ }^{\circ} \mathrm{C}\right)$ a ductile shear fracture along a $45^{\circ}$ tilted plane is observed. As the temperature decreases, intergranular brittle fracture appears in such a way that at low temperatures (below room temperature) a mixture of ductile shear fracture along a $45^{\circ}$ tilted plane and an intergranular brittle fracture along a plane parallel to the tube surface was observed (Figure 7). The temperature at which intergranular brittle fracture appears increases as aging time increases.

\subsection{Charpy impact analysis}

The equivalent Charpy impact energy for the LT and LS sections with increasing ageing time at $475{ }^{\circ} \mathrm{C}$ are shown in Figure 8 . Values of 0,30 , and $110^{\circ} \mathrm{C}$ for DBTT are obtained for LT specimens after aging for 0,50 , and $500 \mathrm{~h}$, whereas those observed for LS specimens were $-10,0$, and $180{ }^{\circ} \mathrm{C}$ for the same aging times. In accordance with that usually observed, the upper shelf energy of LT specimens decreases as the yield strength/aging time increases. In spite of this, the LS specimens do not present an upper shelf but a significant variation. Furthermore, these values are considerably higher than those of LT specimens. However, it seems that the absorbed energy values of LS and LT specimens tend to converge as the temperature increases. On the other hand, the lower shelf energy does not vary much with the orientation of the notch and aging time. However, the Charpy test method is not the most adequate technique to detect toughness differences in this region of the DBTT curve.

\subsubsection{Fracture appearance of $L T$ specimens: Figure 9 shows the macroscopic aspect of the fracture surface} with test temperature and aging time. For simplification purposes, the fracture surfaces were classified in two groups: the one in which no delaminations were found, and the one where delaminations were 
observed. The former comprises the temperature range corresponding to $\mathrm{T} \leq-80^{\circ} \mathrm{C}$ for $\mathrm{t}_{\text {aging }}=0 \mathrm{~h} ; \mathrm{T} \leq-30{ }^{\circ} \mathrm{C}$ for $t_{\text {aging }}=50 \mathrm{~h}$; and $\mathrm{T} \leq 100{ }^{\circ} \mathrm{C}$ for $t_{\text {aging }}=500 \mathrm{~h}$. The fracture of the specimens in these temperature ranges occurs along a $35^{\circ}$ tilted plane with regards to the notch plane. Figure 10 shows the fracture surface at higher magnification than those used in the images of Figure 9, and allow us to conclude that that fracture occurred by a quasi-cleavage mechanism. The later comprises higher temperatures than those defined above. The fracture of the specimens occurs on the notch plane by a ductile process with the formation of delaminations nearly parallel to the extrusion plane. The number of delaminations decreases as the temperature increases. Longitudinal cross sections across the delamination (Figure 11) indicate that the delamination direction is tilted between $3^{\circ}$ and $7^{\circ}$ with regards to the extrusion direction. The morphology of the main fracture surface indicates that fracture occurs by a process of coalescence of microvoids, whereas the fracture surface of delaminations presents a smooth and elongated aspect, which reveals that the energy spent in their formation was small. Some differences are observed by comparing of the fracture surface of delaminations (Figure 12(a) and (b)) with those observed at lower temperatures (Figure 9 and 10). Whereas fracture occurs by quasi-cleavage at low temperatures, the fracture morphology of the delamination is intergranular, as it might be concluded from orientation map analysis on the fracture surface shown in Figure 12(c). Delamination has been also observed along a plane orthogonal to the main fracture containing the notch front (Figure 13), but in this case the fracture mechanism is by coalescence of microvoids.

\subsubsection{Fracture appearance of $L S$ specimen: Figure 14 shows the macroscopic aspect of the fracture surface} with test temperature and aging time. In the temperature range where no delaminations were observed ( $T \leq R T$ for $t_{\text {aging }}=0 \mathrm{~h} ; \mathrm{T} \leq 100^{\circ} \mathrm{C}$ for $t_{\text {aging }}=50 \mathrm{~h}$; and $\mathrm{T} \leq 200^{\circ} \mathrm{C}$ for $t_{\text {aging }}=500 \mathrm{~h}$ ), fracture occurs along $\sim 75^{\circ}$ tilted planes with regard to the notch plane. The morphological aspect of the fracture surfaces is similar to that observed for the brittle delaminations of LT specimens. At higher temperatures than those defined above, the fracture of the specimens follows a tortuous path around the notch plane with the presence of delaminations nearly parallel to the extrusion plane. At higher magnification, ductile fracture by microvoid 
coalescence between delaminations was observed. The fracture surface of delaminations is similar to those observed in the delaminations of LT specimens at low temperature.

\subsection{Delamination mechanism}

It is clear from Figure 8 that there is different behaviour in terms of DBTT, and mainly USE, between LT and LS samples, disregarding the aging treatment at $475{ }^{\circ} \mathrm{C}$. The delamination-toughening phenomenon, as introduced by Kimura et al. [34], is able to explain the differences in USE and DBTT observed between LT and LS samples, on the basis of a crack-divider mode for LT specimens and crack-arrester type for LS specimens. The combinations of the microstructural factors, i.e., microstructural anisotropy and the RD || $<110>$ texture, which are maintained after ageing at $475{ }^{\circ} \mathrm{C}$, were able to control the delamination toughening.

In the crack-arrester mode, the delamination is thought to relax the triaxial stress condition and to blunt the crack tip. Crack re-initiation is necessary to fracture the material, but this now occurs under conditions of nearly uniaxial tension, which is unfavourable cleavage. Hence, high-absorbed energy in USE and low DBTT would be expected in LS samples. On the other hand, in the crack-divider mode the effective thickness of the specimen decreases as the number of delaminations increases. The net effect in this case would be to decrease both the USE and DBTT.

The reason why delaminations are produced parallel to the tube surface in the LT and LS samples might be related to the mechanism of deformation associated with the strong $<110>$ texture observed in $P M 2000^{\mathrm{TM}}$. It has been reported [35-36] that polycrystalline bcc materials with a $<110>$ texture under uniaxial tensile stress in such $<110>$ direction do not axis-symmetrically deform but tends to deform by plane strain. As a result of this, tensile stresses in the (100) planes and compression stresses in the (110) planes, both transverse to tensile test direction, are generated. The average value of such stresses in these planes is 20\% of the applied stress, although it could be as high as the applied stress. Therefore, $<110>$-textured 
$\mathrm{BCC}$ materials are sensitive per se to delamination. In fact, it has been stated recently that ferritic materials with $<110>$ texture suffer delamination; however, as has been reported by Kimura and co-workers [34], one can take advantage of delamination to improve the toughness of the material for some applications.

In accordance with these findings, recent work [37] has revealed that PM $2000^{\mathrm{TM}}$ tends to deform under plan strain conditions on LS or TS plane planes when it is axially deformed in L or T directions (parallel to $<110>$ direction), respectively.

In Charpy tests, the main stress component after the impact is $\sigma_{y}$. The other two stress components, $\sigma_{x}$ and $\sigma_{z}$, are generated by the localized plastic constraint at the notch and/or the crack tip, and is of lower magnitude than $\sigma_{y}$ (Figure 15). The splitting in LT and LS samples could be explained by plastic deformation in the S-direction that is considerably higher than in the T-direction. Therefore, the plastic constraint in the S-direction would lead to an increase of $\sigma_{x}$ in the case of the LT samples, and of $\sigma_{z}$ in the case of the LS samples that would cause the distribution of cracks found experimentally. These delaminations are similar to those found under crack-divider and crack-arrester basic geometries. Moreover, the weak interfaces between second phases, such as the Y-Al-Ti oxides located in the grain boundaries aligned to the RD, can also enhance delamination [38-39].

\subsection{Embrittlement mechanism}

Additionally, the presence of the $\alpha^{\prime}$ phase is fully responsible for the hardening and its resultant embrittlement of thermally aged, high Cr ODS steels. The $\alpha^{\prime}$ phase results in an increase in internal stress, which in turn evokes a hardening of the material by hindering dislocation movement. According to Park et al. [40], such an increase in internal stress is caused by the atomic misfit and a different modulus for the $\alpha$ and $\alpha^{\prime}$ phases, and is directly proportional to the difference in composition of the phases, as previously reported by Capdevila et al. [20]. This increased stress raises the critical resolved shear stress for slip, thus increasing the probability of forming a $\{112\}<111>$ twin over generating slip in the bcc ferrite matrix [41]. 
However, in transmission electro microscopy observations, the creation of deformation twins on the significantly hardened tensile specimens could not be ascertained, but only a dislocation cell structure was observed. Based on the results, the occurrence of the $\alpha^{\prime}$ phase in ODS steels hinders the motion of dislocations and hardens the materials, which results in the loss of toughness and the observed shift in ductile-to-brittle transition temperature.

\section{Conclusions}

The effects of $\alpha-\alpha^{\prime}$ phase separation occurring during ageing at $475{ }^{\circ} \mathrm{C}$ on the microstructure and mechanical properties of $\mathrm{PM} 2000^{\mathrm{m} M}$ hot-rolled tube, were investigated by means of atom probe tomography, microhardness, tensile and V-notched Charpy impact tests. The results obtained show that:

1) APT reveals that a nm-scaled phase separation between $\alpha$ and $\alpha^{\prime}$ phases is the predominant mechanism responsible for strengthening in a PM $2000^{\mathrm{TM}}$ ODS alloy during isothermal aging at 475 ${ }^{\circ} \mathrm{C}$. The phase separation process is described in terms of two different parameters: the $\Delta \mathrm{C}$ and $\lambda$. Analysis of experimental data indicates that as the phase separation proceeds, both the size and chromium content of the $\alpha^{\prime}$ domains increases.

2) The aging treatment at $475^{\circ} \mathrm{C}$ produces an increase in the $Y S$ and UTS with a subsequent decrease in ductility. However, despite the loss of ductility, the material exhibits ductile behavior as observed by the necked zone in tensile specimens, which is different from the so-called " $475{ }^{\circ} \mathrm{C}$ embrittlement" observed for other high chromium ferritic alloys.

3) The delamination by crack-divider type was observed in LT specimens, whereas crack-arrester type was observed in LS specimens. The differences in crack-type between LS and LT specimens can be related to the plastic anisotropy. Because of the considerably higher plastic deformation in the Sdirection than in the T-direction, the plastic constrain is the S-direction would lead to an increase of 
$\sigma_{\mathrm{x}}$ in the case of LT samples, and of $\sigma_{z}$ in the case of LS sample that would cause delamination perpendicular to the notch base for LT samples and parallel to the notch base for LS samples.

4) The delamination-toughening phenomenon, as introduced by Kimura et al. [34], is able to explain the evolution of USE and DBTT observed in LS samples. In the crack-arrester geometry of LS samples, the delamination is thought to relax the triaxial stress condition and to blunt the crack tip. To fracture a material, crack re-initiation is necessary and occurs under conditions of nearly uniaxial tension, which is an unfavorable cleavage. Hence, high absorbed energy is obtainable through the delamination in LS samples.

5) After thermal aging treatments at $475^{\circ} \mathrm{C}$, significant embrittlement associated with hardening was observed. Based on the APT investigations, the main cause of embrittlement is the formation of a coherent $\mathrm{Cr}$-enriched ferrite $\alpha^{\prime}$ phase. The apparent activation energy for thermally activated hardening is measured in the range of $200-210 \mathrm{~kJ} / \mathrm{mol}$, which is similar to the diffusion activation energy of Fe and $\mathrm{Cr}$ in $\alpha$-iron. The $\alpha-\alpha^{\prime}$ phase separation leads to a reduction of the USE and an increase in the DBTT in both LT and LS samples of PM $2000^{\mathrm{TM}}$. These results are consistent with the previously reported reduction in the tensile elongation [20].

\section{Acknowledgments}

PM $2000^{\text {TM }}$ is a trademark of Plansee $\mathrm{GmbH}$. LEAP $^{\circledR}$ is a registered trademark of Cameca Instruments. The authors acknowledge the financial support of the Spanish Ministerio de Economia e Innovación in the form of a Coordinate Project in the Energy Area of Plan Nacional 2009 (ENE2009-13766-C04-01). This research was supported by ORNL's Shared Research Equipment (ShaRE) User Facility, which is sponsored by the Office of Basic Energy Sciences, US Department of Energy. 


\section{References}

[1] Ukai S, Fujiwara M. Perspective of ODS alloys application in nuclear environments. J Nucl Mater 2002; 307-311:749-57

[2] Jitsukawa S, Kimura A, Kohyama A, Klueh RL, Tavassoli AA, van der Schaaf B, Odette GR, Rensman JW, Victoria M, Petersen C. Recent results of the reduced activation ferritic/martensitic steel development. J Nucl Mater 2004;329-333:39-46.

[3] Bauer GS. Overview on spallation target design concepts and related materials issues. J Nucl Mater 2010;398:19-27.

[4] Chen J, Pouchon MA, Kimura A, Jung P, Hoffelner W. Irradiation creep and microstructural changes in an advanced ODS ferritic steel during helium implantation under stress. J Nucl Mater 2009;386-388:143-6.

[5] Ukai S, Harada M, Okada H, Inoue M, Nomura S, Shikakura S, Nishida T, Fujiwara M, Asabe K. Tube manufacturing and mechanical properties of oxide dispersion strengthened ferritic steel, J Nucl Mater 1993;204:74-80.

[6] Chao J, González-Carrasco JL, Capdevila C. Influence of annealing at $1100^{\circ} \mathrm{C}$ and $475^{\circ} \mathrm{C}$ on the mechanical properties at room temperature of an iron base ODS alloy. ISIJ Int 2007;47:1214-20

[7] Chao J, Capdevila C, González-Carrasco JL. On the delamination of FeCrAl ODS alloys. Mater Sci Eng A 2009; 515:190-8.

[8] Capdevila C, Miller MK, Toda I, Chao J. Influence of the $\alpha$ - $\alpha^{\prime}$ phase separation on the tensile properties of Fe-base ODS PM 2000 alloy. Mater Sci Eng A 2010;527:7931-38.

[9] Mulford RA, McMahon CJ, Pope DP, Feng HC. Temper embrittlement of Ni-Cr Steels by phosphorus Metall Mater Trans A 1976;7: 1183-95. 
[10] Li-xin Wang, Chang-jiang Song, Feng-mei Sun, Li-juan Li, Qi-jie Zhai. Microstructure and mechanical properties of $12 \mathrm{wt} . \% \mathrm{Cr}$ ferritic stainless steel with $\mathrm{Ti}$ and $\mathrm{Nb}$ dual stabilization Materials \& Design;30: 4956

[11] Song SH, Wu J, Weng LQ, Yuan ZX. Fractographic changes caused by phosphorus grain boundary segregation for a low alloy structural steel. Mater Sci Eng A 2008;497:524-7.

[12] Bonny G, Terentyev D, Malerba L. New contribution to the thermodynamics of Fe-Cr alloys as base for ferritic steels. J Phase Equilib Diff 2010;31:439-44.

[13] Pareige C, Roussel M, Novy S, Kuksenko V, Olsson P, Domain C, Pareige P, Kinetic study of phase transformation in a highly concentrated Fe-Cr alloy: Monte Carlo simulation versus experiments. Acta Mater 2011;59:2404-11.

[14] Capdevila C, Miller U, Jelenak H, Bhadeshia HKDH. Strain heterogeneity and the production of coarse grains in mechanically alloyed iron-based PM2000 alloy. Mater Sci Eng A 2001;316:161-5

[15] Miller MK: Atom Probe Tomography: Analysis at the Atomic Level, Ney York: Kluwer Academic Plenum Publishers; 2000, p. 56.

[16] Caballero FG, Allain S, Cornide J, Puerta Velásquez JD, Garcia-Mateo C, Miller, MK. Design of cold rolled and continuous annealed carbide-free bainitic steels for automotive application Materials \& Design 2013;49: 667-680.

[17] Pimentel G, Toda-Caraballo I, Chao J, Capdevila C. Role of strain heterogeneity on recrystallisation of oxide dispersion strengthened Fe-Cr-Al alloys for high-temperature applications. J Mater Sci 2012; 47:560516.

[18] Capdevila C, Miller MK, Russell KF. Aluminum partitioning during phase separation in $\mathrm{Fe}-20 \% \mathrm{Cr}-6 \% \mathrm{Al}$ ODS alloy. J Mater Sci 2008;43:3889-93. 
[19] Capdevila C, Miller MK, Russell KF, Chao J, González-Carrasco JL. Phase separation in PM 2000 Fe-base ODS alloy: Experimental study at the atomic level. Mater Sci Eng A 2008;490:277-88.

[20] Capdevila C, Caballero FG, De Andres CG. Modeling of kinetics of austenite-to-allotriomorphic ferrite transformation in 0.37C-1.45Mn-0.11V microalloyed steel. Metall Mater Trans A 2001;32:661-9.

[21] Capdevila C, Miller MK, Toda I, Chao J. Influence of the $\alpha-\alpha^{\prime}$ phase separation on the tensile properties of Fe-base ODS PM 2000 alloy. Mater Sci Eng A 2010;527:7931-8.

[22] Parish CM, Capdevila C, Miller MK. A MVSA approach to mine information from APT data. Ultramicroscopy 2011;111: 440-4.

[23] Capdevila C, Miller MK, Chao J. Phase separation kinetics in a Fe-Cr-Al alloy. Acta Mater 2012;60:467384.

[24] Miller MK, Hyde JM, Hetherington MG, Cerezo A, Smith GDW, Elliott CM. Spinodal decomposition in Fe-Cr alloys: Experimental study at the atomic level and comparison with computer models-I. Introduction and methodology. Acta Metall Mater 1995;43:3385-401.

[25] Hellman OC, Vandenbroucke JA, Rüsing J, Isheim D, Seidman DN. Identification of 2D boundaries from 3D atom probe data, and spatial correlation of atomic distributions with interfaces. Microsc Microanal 2000;6:437-44.

[26] Miller MK: Atom Probe Tomography: Analysis at the Atomic Level, Ney York: Kluwer Academic Plenum Publishers; 2000, p. 28.

[27] Lifshitz IM, Slyozov VV. The kinetics of precipitation from supersaturated solid solutions. J Phys Chem Solids 1961;19:35-50. 
[28] Wagner C. Theorie der Alterung von Niederschlägen durch Umlösen (Ostwald-Reifung), Z Elektrochem 1961;65:581-91.

[29] De Geuser F, Lefebvre W, Auger P, Danoix F, Bigot A, Blavette D. Atom probe tomography II. The precipitation in Al base alloys. Adv Eng Mater 2006;8:1206-9.

[30] Starink M. Kinetic equations for diffusion-controlled precipitation reactions. J Mater Sci 1997; 32:40614070.

[31] Diffusion in Metals. In: E.A. Browdes, G.B. Brook, editors. Smithells Metals Reference Book. $7^{\text {th }}$ edition, Oxford, Butterworth, Heinemann; 1992, p. 13-1.

[32] J. W. Cahn. Hardening by Spinodal Decomposition. Acta Metall 1963;11:1275-81.

[33] Lagneborg R. Deformation in an iron-30 percent chromium alloy aged at 475 degrees C. Acta Metall 1967; 15:1737-45.

[34] Kimura Y, Inoue T, Yin F, Tsuzaki K. Delamination toughening of ultrafine grain structure steels processed through tempforming at elevated temperatures. ISIJ Int 2010;50:152-61.

[35] N. Yu. Zolotorevsky and N. Yu. Krivonosova. Effect of ferrite crystals' plastic anisotropy on residual stresses in cold-drawn steel wire. Mater Sci Eng A 1996;205:239-46.

[36] Sevillano JG, Alkorta J, González D, Van Petegem S, Stuhr U, Van Swygenhoven H. In situ neutron diffraction study of internal micro-stresses developed by plastic elongation in $<110>$ textured BCC wires. Adv Eng Mater 2008;10:951-954.

[37] Chao J, Capdevila C, Serrano M, Garcia-Junceda A, Jimenez JA, Pimentel G, Urones-Garrote E, Metall Mater Trans A 2013, accepted. 
[38] Yen CM, Stickels CA. Lamellate fracture in 5150 steel processed by modified ausforming. Metall Trans 1970;1:3037-47.

[39] Zhou W, Loh NL. Effect of delaminations on improvement of notch toughness at low temperatures. Scr Mater 1996;34:633-9.

[40] Park KH, Lasalle JC, Schwartz LH, Kato M. Mechanical properties of spinodally decomposed fe-30 wt\% Cr alloys: yield strength and aging embrittlement. Acta Metall 1986;34:1853-65.

[41] Nichol TJ, Datta A, Aggen G. Embrittlement of ferritic stainless steels. Metall Trans A 1980;11:573-85. 
Tables

Table 1. Chemical composition of PM $2000^{\mathrm{TM}}$ as determined by XRF.

Table 2. Compositions of the $\alpha$ and $\alpha^{\prime}$ phases for different aging times at $475^{\circ} \mathrm{C}$, as estimated from the proximity histogram. The balances of the analyses are iron.

Table 3. Size parameters estimated from the 3D radial autocorrelation function. 
Table 1. Chemical composition of PM $2000^{\mathrm{TM}}$ as determined by XRF.

\begin{tabular}{lllllllll}
\hline \multicolumn{1}{cr}{} & $\mathrm{Al}$ & $\mathrm{Ti}$ & $\mathrm{C}$ & $\mathrm{O}$ & $\mathrm{N}$ & $\mathrm{Y}$ & $\mathrm{Fe}$ \\
\hline wt. \% & 18.60 & 5.20 & 0.54 & 0.04 & 0.09 & 0.006 & 0.40 & balance \\
& & & & & & & & \\
at. \% & 18.50 & 10.10 & 0.58 & 0.17 & 0.28 & 0.022 & 0.23 & balance \\
& & & & & & & & \\
\hline
\end{tabular}


Table 2. Compositions of the $\alpha$ and $\alpha^{\prime}$ phases for different aging times at $475^{\circ} \mathrm{C}$, as estimated from the proximity histogram. The balances of the analyses are iron.

\begin{tabular}{|c|c|c|c|c|c|c|}
\hline at. $\%$ & $10 \mathrm{~h}$ & $50 \mathrm{~h}$ & $100 \mathrm{~h}$ & $330 \mathrm{~h}$ & $500 \mathrm{~h}$ & $2040 \mathrm{~h}$ \\
\hline $\mathrm{Cr}_{\alpha}$ & $17.1 \pm 0.3$ & $17.79 \pm 0.27$ & $15.4 \pm 0.16$ & $16.6 \pm 0.15$ & $15.7 \pm 0.14$ & $15.6 \pm 0.16$ \\
\hline $\mathrm{Al}_{\alpha}$ & $12.2 \pm 0.3$ & $11.36 \pm 0.27$ & $11.82 \pm 0.15$ & $12.6 \pm 0.13$ & $12.6 \pm 0.12$ & $12.5 \pm 015$ \\
\hline $\mathrm{Ti}_{\alpha}$ & $0.62 \pm 0.07$ & $0.82 \pm 0.06$ & $0.73 \pm 0.03$ & $0.63 \pm 0.03$ & $0.75 \pm 0.03$ & $0.48 \pm 0.03$ \\
\hline $\mathrm{Cr}_{\alpha^{\prime}}$ & $33.0 \pm 2.0$ & $29.6 \pm 0.31$ & $32.33 \pm 0.76$ & $46.4 \pm 1.22$ & $71.6 \pm 1.43$ & $82.2 \pm 0.54$ \\
\hline $\mathrm{Al}_{\alpha^{\prime}}$ & $13.7 \pm 1.5$ & $11.42 \pm 0.22$ & $12.44 \pm 0.52$ & $10.0 \pm 0.72$ & $5.78 \pm 0.79$ & $3.45 \pm 0.26$ \\
\hline $\mathrm{Ti}_{\alpha^{\prime}}$ & $0.44 \pm 0.2$ & $0.82 \pm 0.06$ & $0.54 \pm 0.13$ & $0.39 \pm 0.18$ & $0.27 \pm 0.16$ & $0.12 \pm 0.05$ \\
\hline$\Delta \mathrm{C}_{\mathrm{Cr}}$ & $15.9 \pm 2.3$ & $11.27 \pm 0.58$ & $16.93 \pm 0.92$ & $29.8 \pm 1.37$ & $55.9 \pm 1.57$ & $66.6 \pm 0.70$ \\
\hline
\end{tabular}


Table 3. Size parameters estimated from the 3D radial autocorrelation function.

\begin{tabular}{ccccccc}
\hline time & $10 \mathrm{~h}$ & $50 \mathrm{~h}$ & $100 \mathrm{~h}$ & $330 \mathrm{~h}$ & $500 \mathrm{~h}$ & $2040 \mathrm{~h}$ \\
\hline$\lambda / \mathrm{nm}$ & 1.5 & 2.5 & 4.3 & 4.4 & 4.8 & 7 \\
\hline
\end{tabular}




\section{Figures}

Figure 1. (a) Backscattered SEM of grain boundary particles (in white) in TS for the hot rolled condition, (b) TEM image of LS, and (c) IPF maps (Z-direction) in LT, LS, and TS planes.

Figure 2. (a) Atom map and composition profile illustrating $\alpha^{\prime}$ precipitates after ageing at $475^{\circ} \mathrm{C}$ for $500 \mathrm{~h}$. Evolution of (b) $\Delta \mathrm{C}_{\mathrm{cr}}$ in both recrystallized and as-hot rolled samples and (d) $\lambda$ with time during ageing at $475^{\circ} \mathrm{C}$ in recrystallized samples.

Figure 3. Activation energy of $\alpha-\alpha^{\prime}$ phase separation process from microhardness measurements.

Figure 4. Evolution of (a) YS and UTS and (b) $\varepsilon_{\mathrm{u}}$ and $\varepsilon_{\mathrm{t}}$ with testing temperature for samples aged at $475{ }^{\circ} \mathrm{C}$ for different times.

Figure 5. Evolution of (a) YS and UTS with ageing time at $475^{\circ} \mathrm{C}$ and (b) evolution of $\Delta Y S$ with $\Delta \mathrm{C}$ for room temperature testing.

Figure 6. Fractography of tensile samples aged at $475^{\circ} \mathrm{C}$ for different times and tested at different temperatures. 
Figure 7. SEM image of the delamination surface of a tensile specimen aged for $200 \mathrm{~h}$ and tested at room temperature.

Figure 8. Charpy Impact energy for (a) LT specimens and (b) LS specimens

Figure 9. Fractography of $L T$ samples aged at $475{ }^{\circ} \mathrm{C}$ for different times and tested at different temperatures.

Figure 10. SEM image showing quasi-cleavage fracture in LT specimen aged for $500 \mathrm{~h}$ and tested at $-80^{\circ} \mathrm{C}$.

Figure 11. Fracture morphology of (a) LT sample aged for $50 \mathrm{~h}$ and tested at RT and (b) aged for $500 \mathrm{~h}$ and tested at $350^{\circ} \mathrm{C}$. Details of parallel delaminations are shown.

Figure 12. SEM images of LT specimen of the as-received material tested at RT. a) Low magnification SEM image showing the delaminations, b) SEM image showing the surface of delamination, and c) orientation map along RD on cross sectional plane parallel to tube surface. 
Figure 13. Low magnification SEM images showing (a) ductile delamination orthogonal to the main fracture and containing the notch front of LT specimen aged for $50 \mathrm{~h}$ and tested at RT, and (b) detail of main fracture plane.

Figure 14. Fractography of LS specimens aged at $475^{\circ} \mathrm{C}$ for different times and tested at different temperatures.

Figure 15. Schematic illustration showing laminate splitting geometries found in LT and LS samples tested according with Cartesian $x, y, z$ and L,T,S reference systems. (After Kimura et al. [34]). 

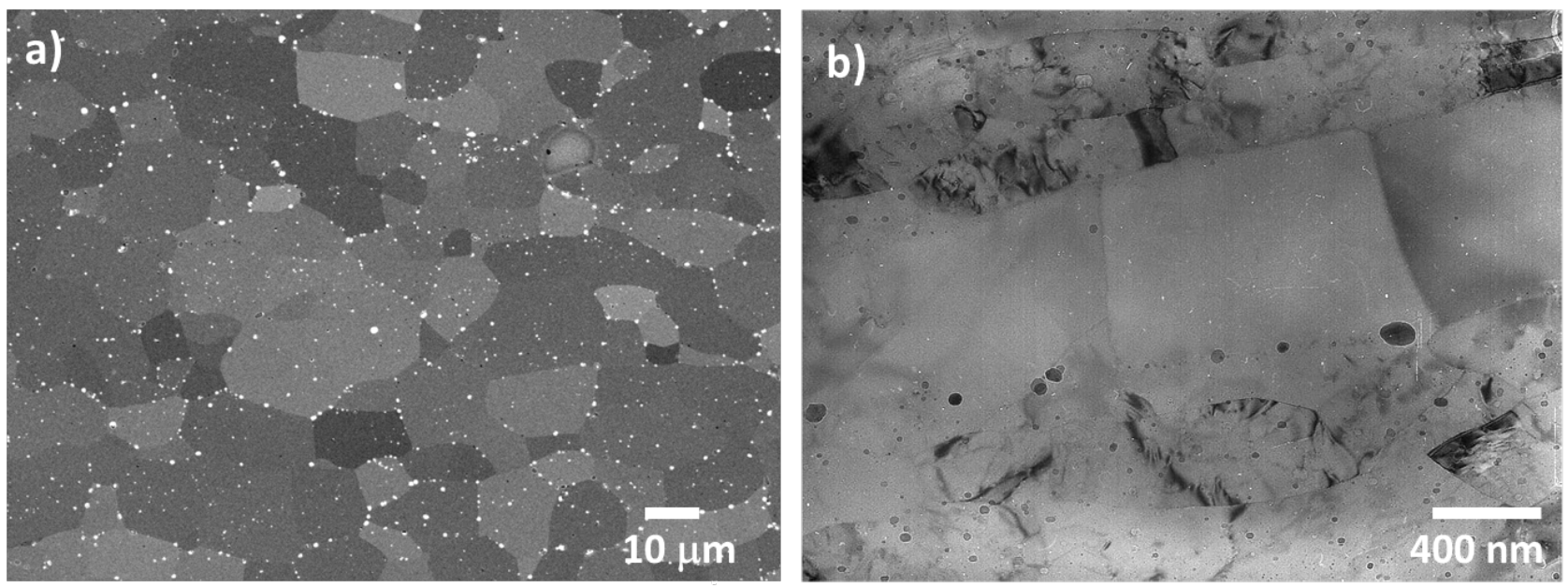

c)
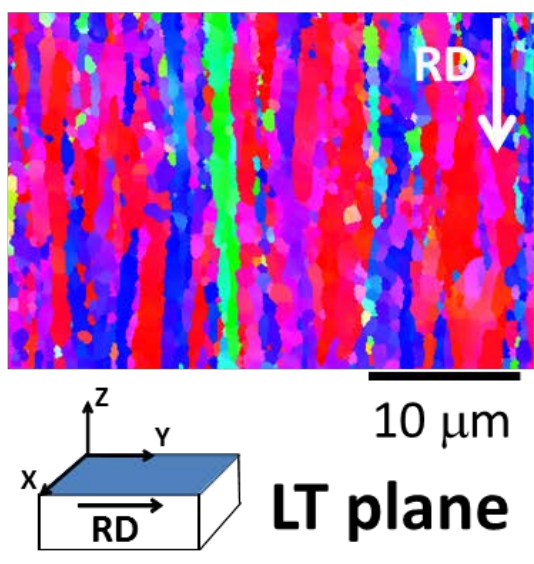

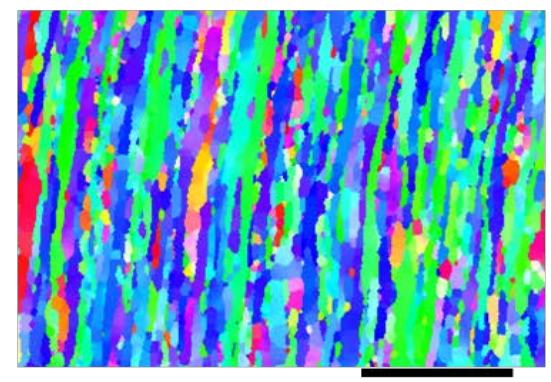

$10 \mu \mathrm{m}$

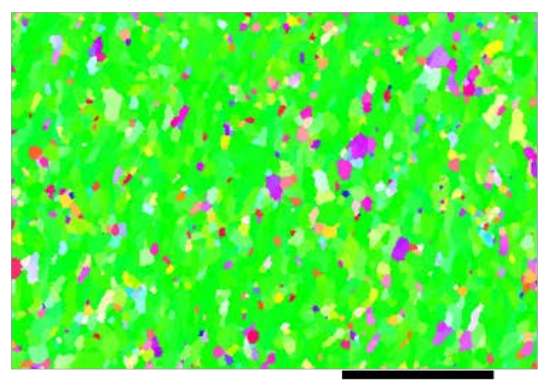

$10 \mu \mathrm{m}$

\section{LS plane}

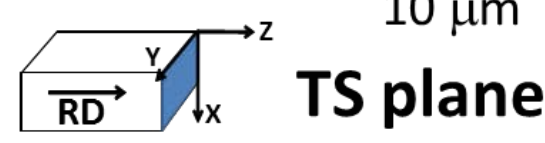
111

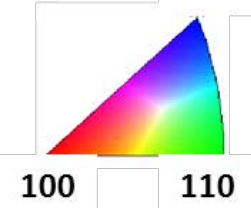

Figure 1. (a) Backscattered SEM of grain boundary particles (in white) in TS for the hot rolled condition, (b) TEM image of LS, and (c) IPF maps (Z-direction) in LT, LS, and TS planes. 
a)

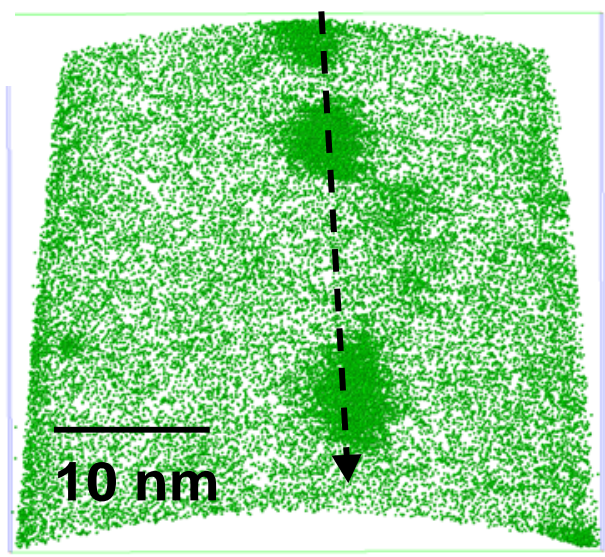

- $\mathrm{Cr}$ atom
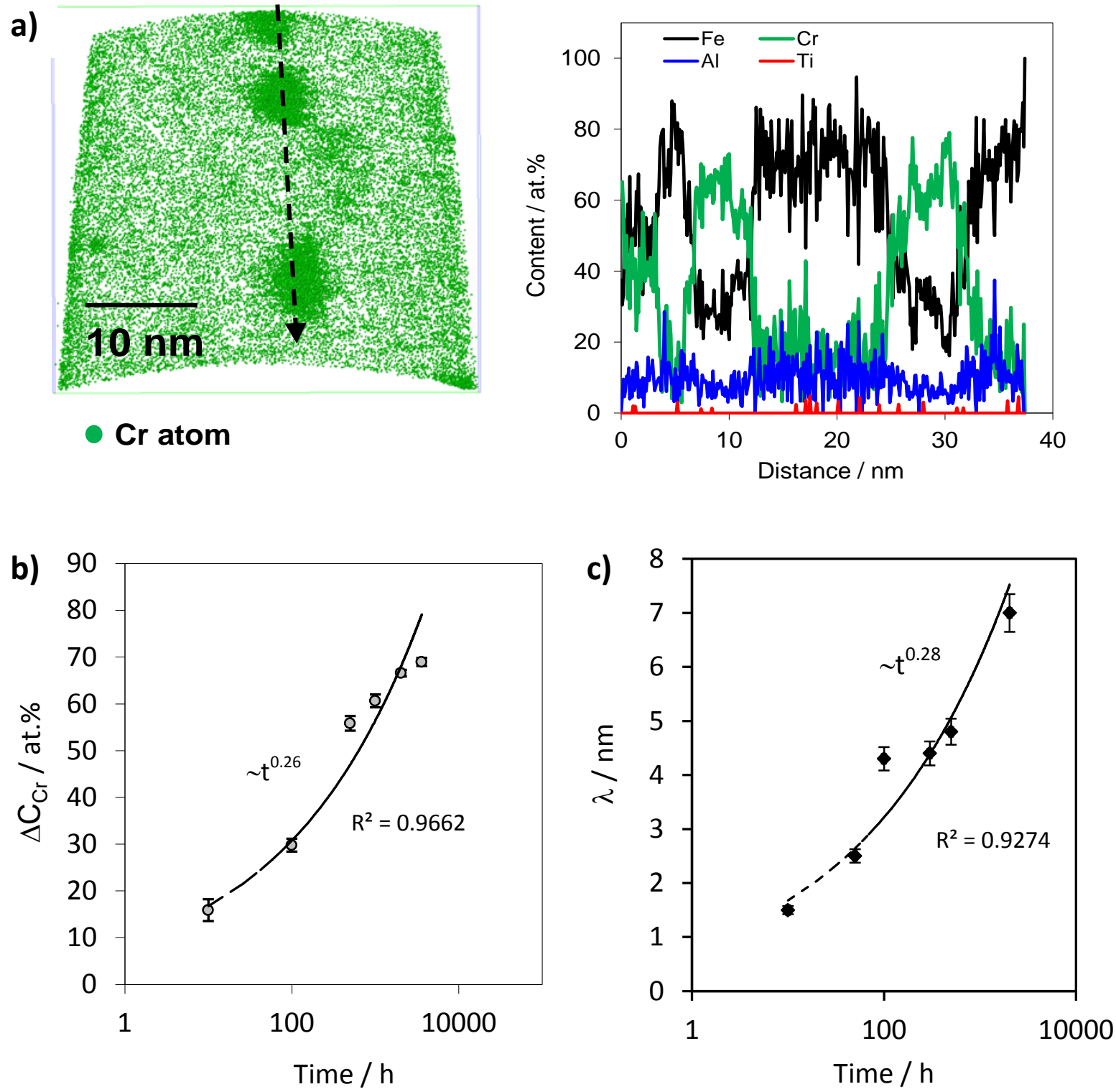

Figure 2. (a) Atom map and composition profile illustrating $\alpha^{\prime}$ precipitates after ageing at $475{ }^{\circ} \mathrm{C}$ for $500 \mathrm{~h}$. Evolution of (b) $\Delta \mathrm{C}_{\mathrm{cr}}$ in both recrystallized and as-hot rolled samples and (d) $\lambda$ with time during ageing at $475^{\circ} \mathrm{C}$ in recrystallized samples. 


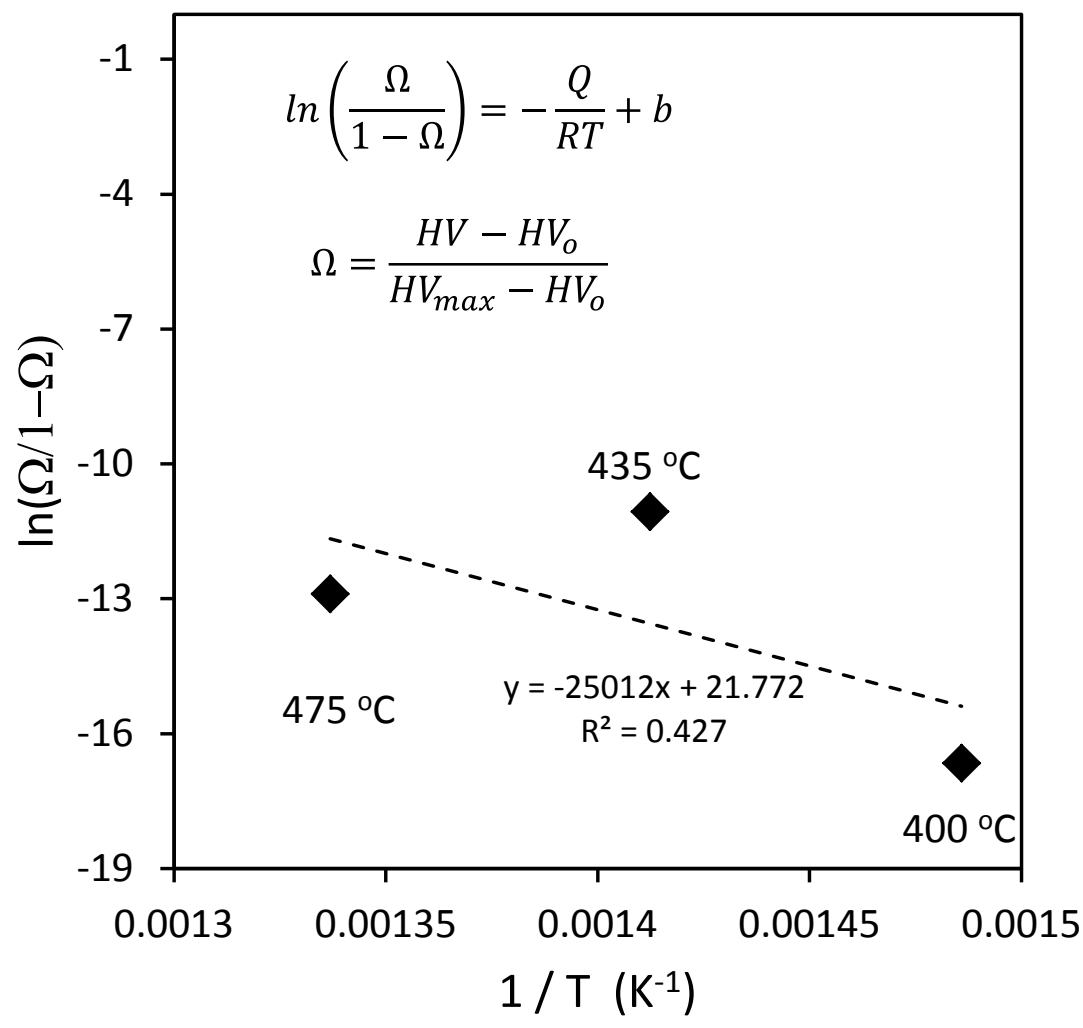

Figure 3. Activation energy of $\alpha-\alpha^{\prime}$ phase separation process from microhardness measurements. 
a)

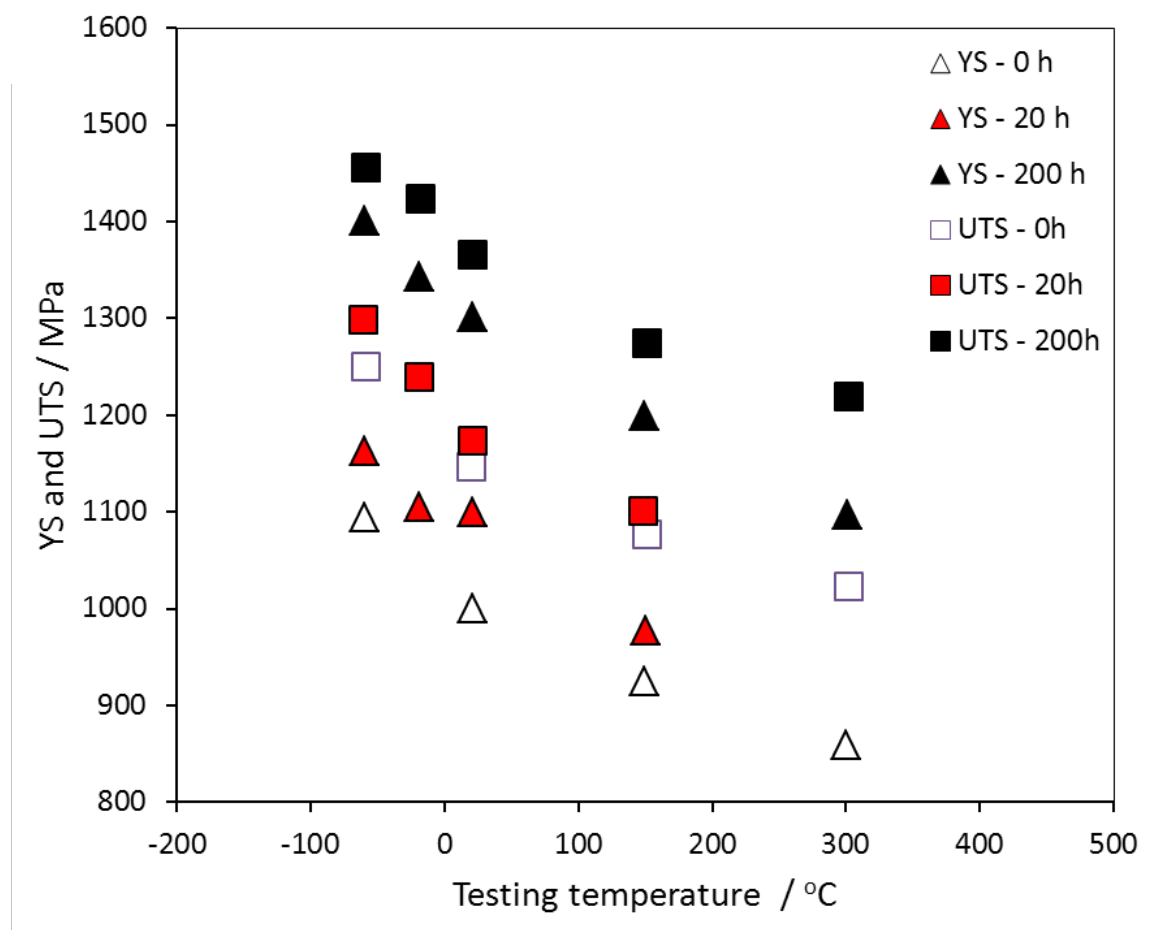

b)

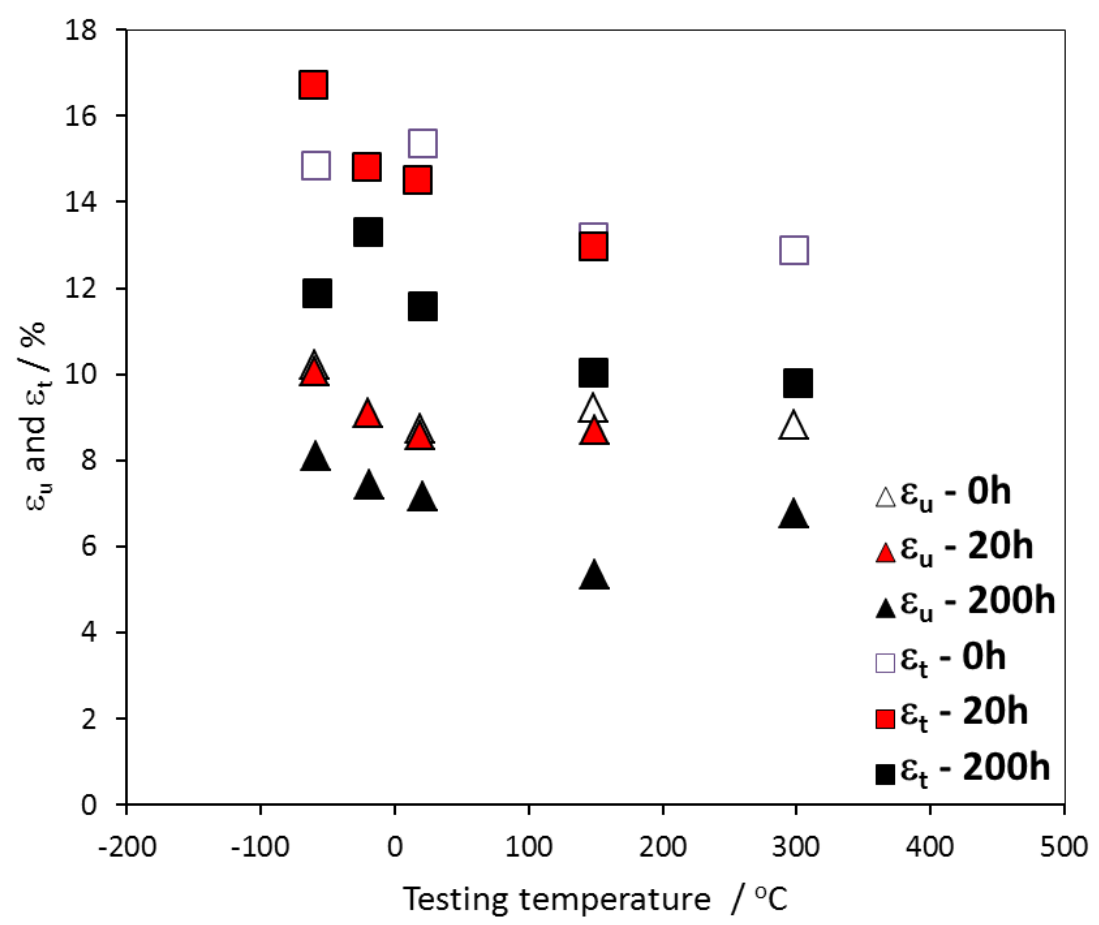

Figure 4. Evolution of (a) YS and UTS and (b) $\varepsilon_{\mathrm{u}}$ and $\varepsilon_{\mathrm{t}}$ with testing temperature for samples aged at $475{ }^{\circ} \mathrm{C}$ for different times. 
a)
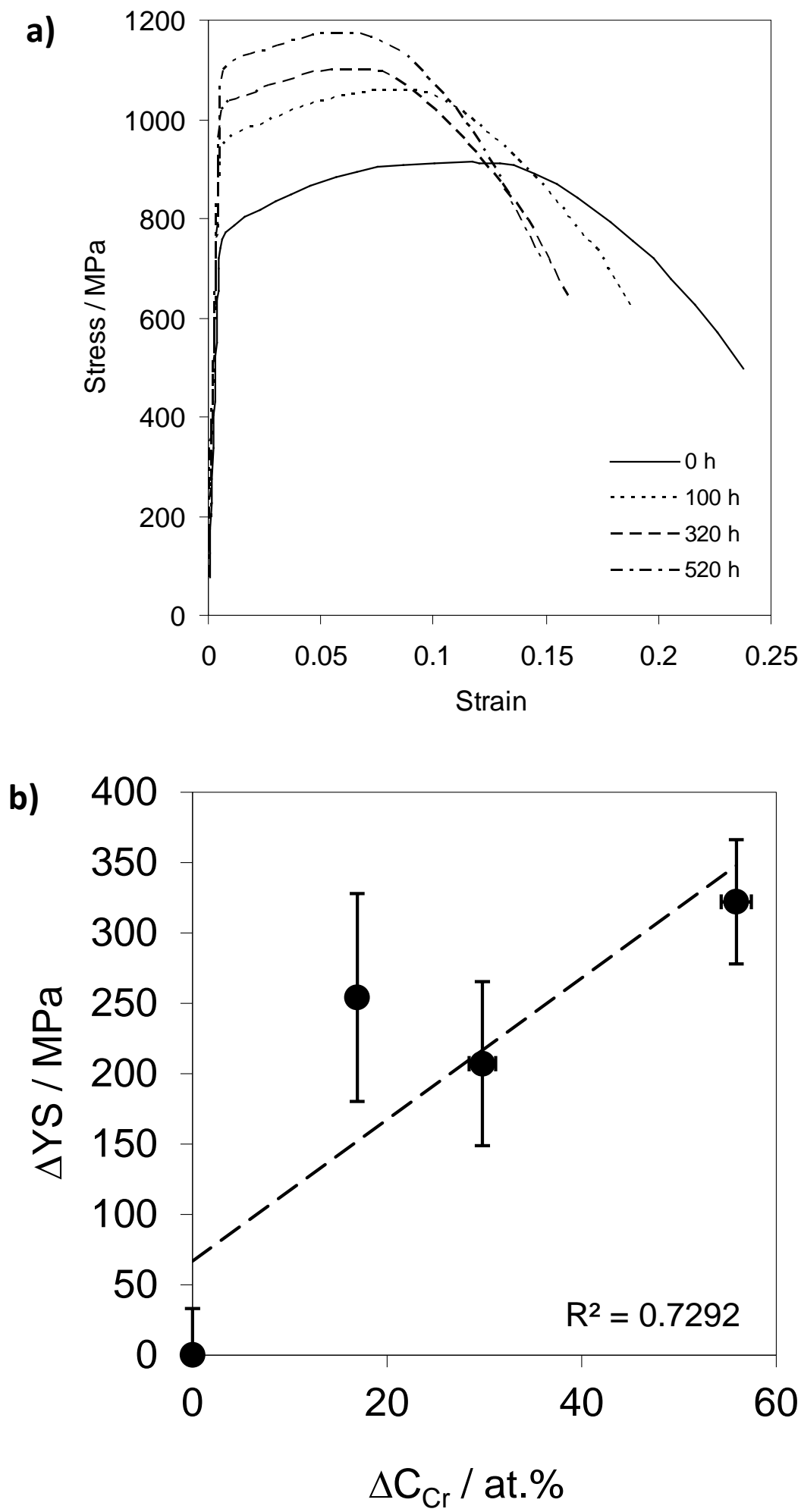

Figure 5. Evolution of (a) YS and UTS with ageing time at $475^{\circ} \mathrm{C}$ and (b) evolution of $\Delta \mathrm{YS}$ with $\Delta \mathrm{C}$ for room temperature testing. 
$-60$

$-20$

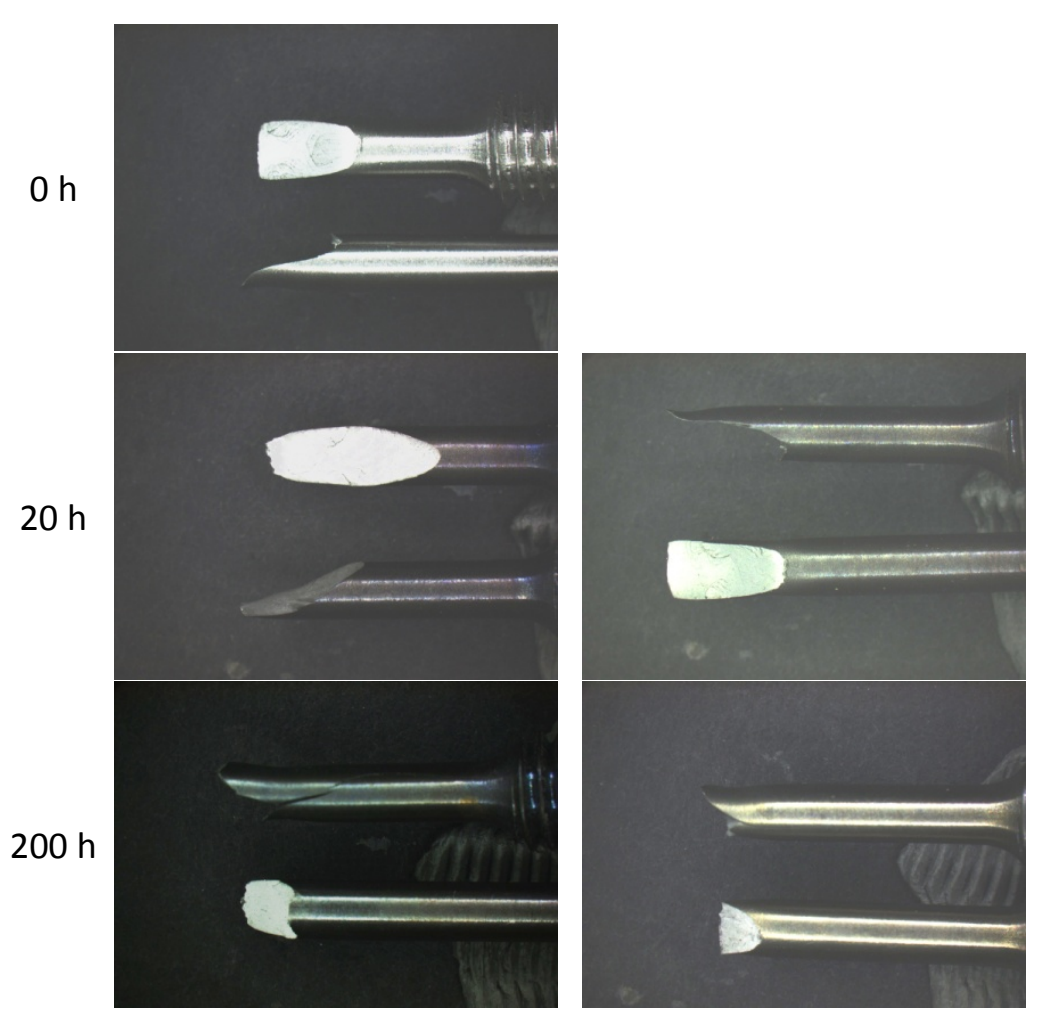

Testing temperature $/{ }^{\circ} \mathrm{C}$

RT

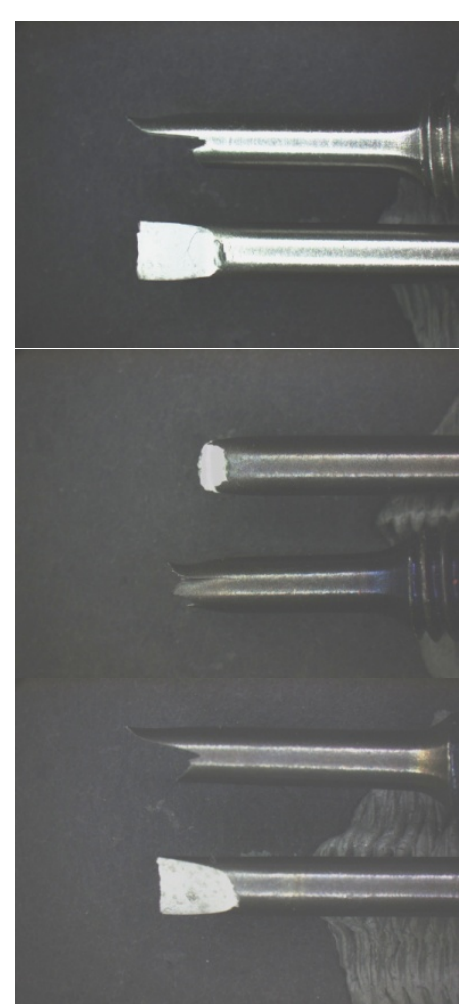

150

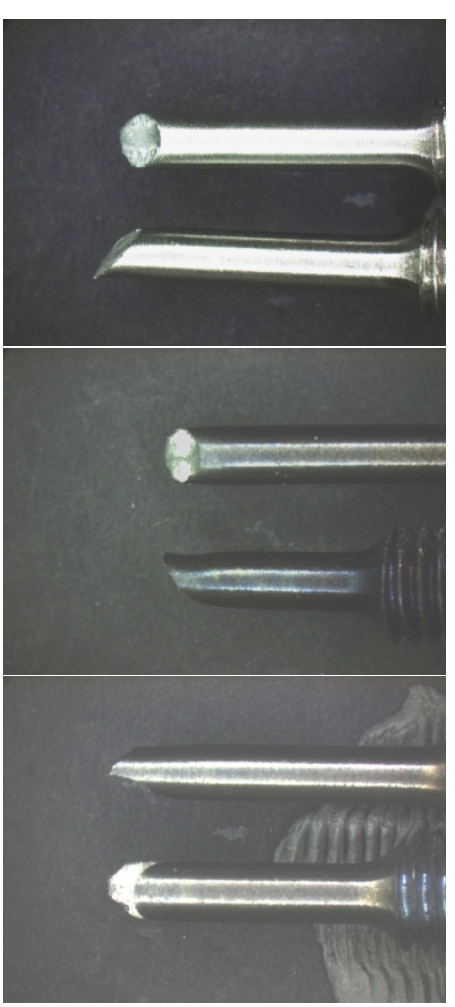

300

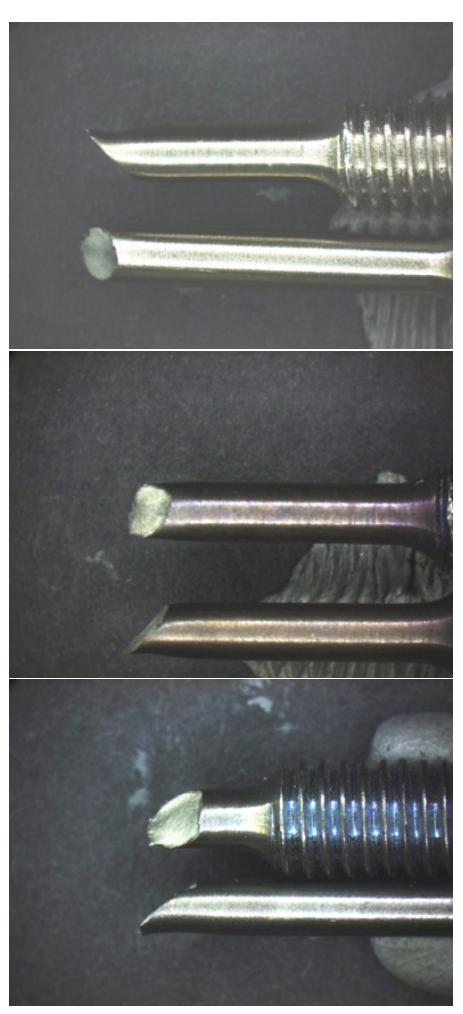

Figure 6. Fractography of tensile samples aged at $475^{\circ} \mathrm{C}$ for different times and tested at different temperatures. 


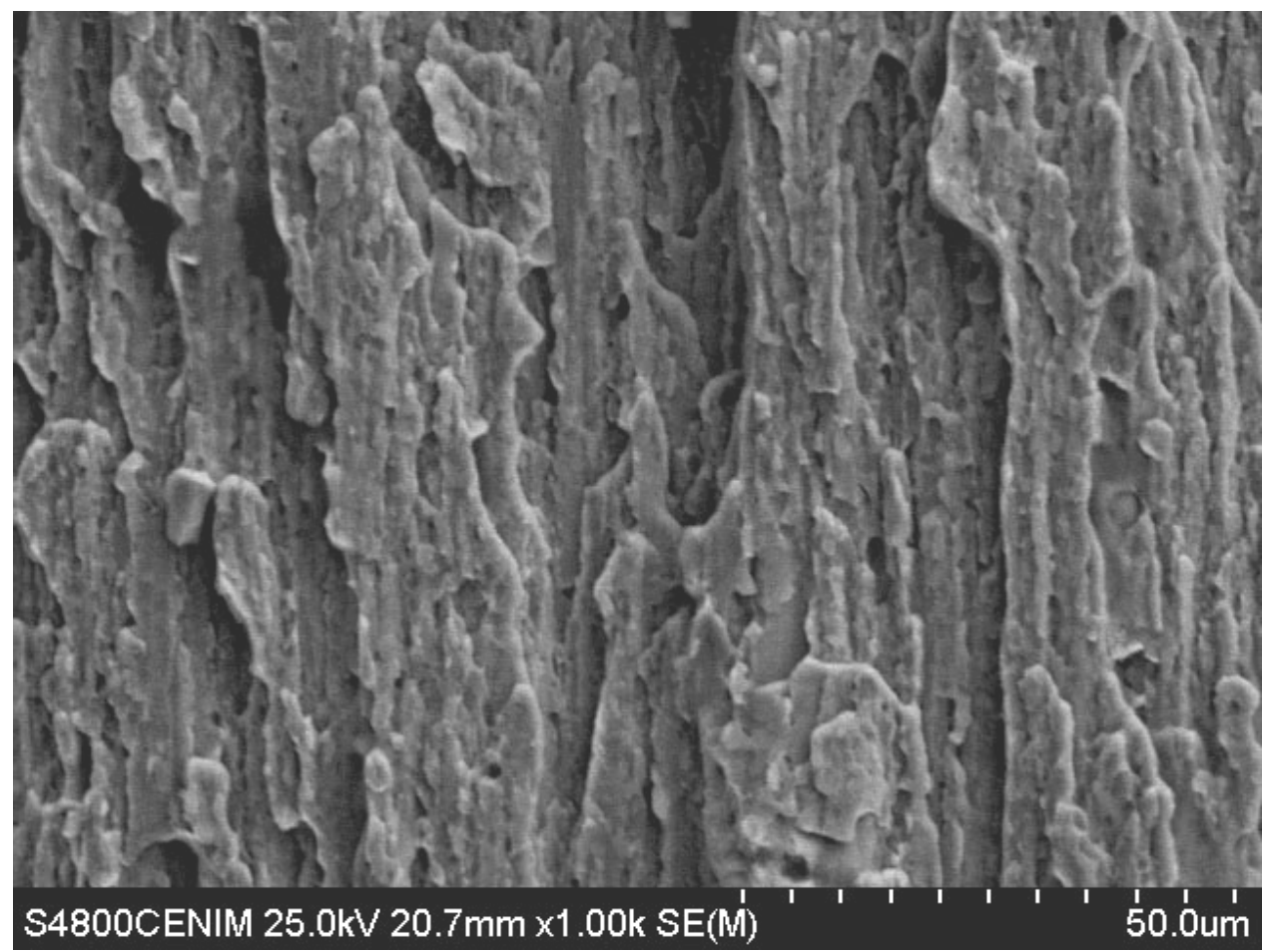

Figure 7. SEM image of the delamination surface of a tensile specimen aged for $200 \mathrm{~h}$ and tested at room temperature. 

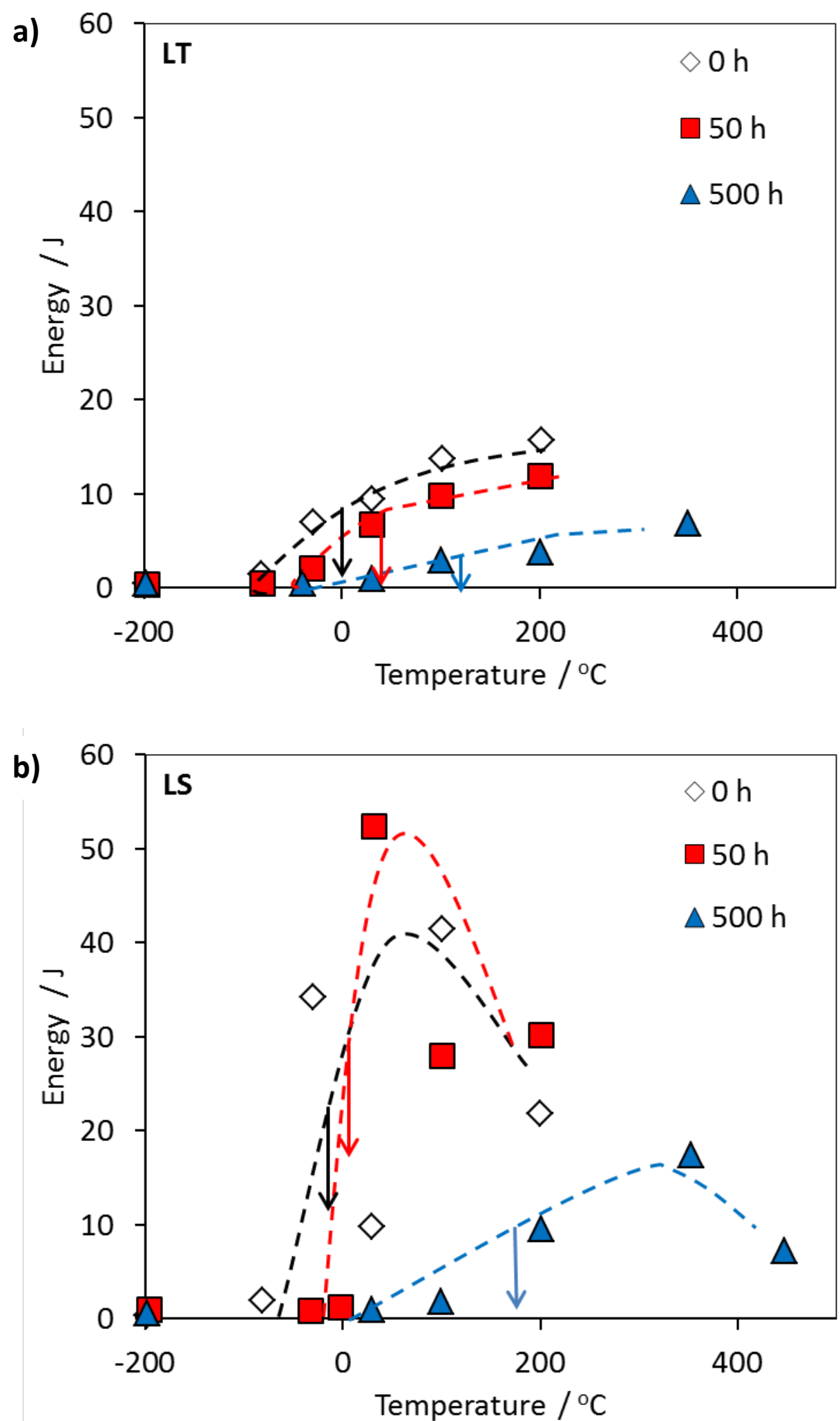

Figure 8. Charpy Impact energy for (a) LT specimens and (b) LS specimens 
Testing temperature $/{ }^{\circ} \mathrm{C}$

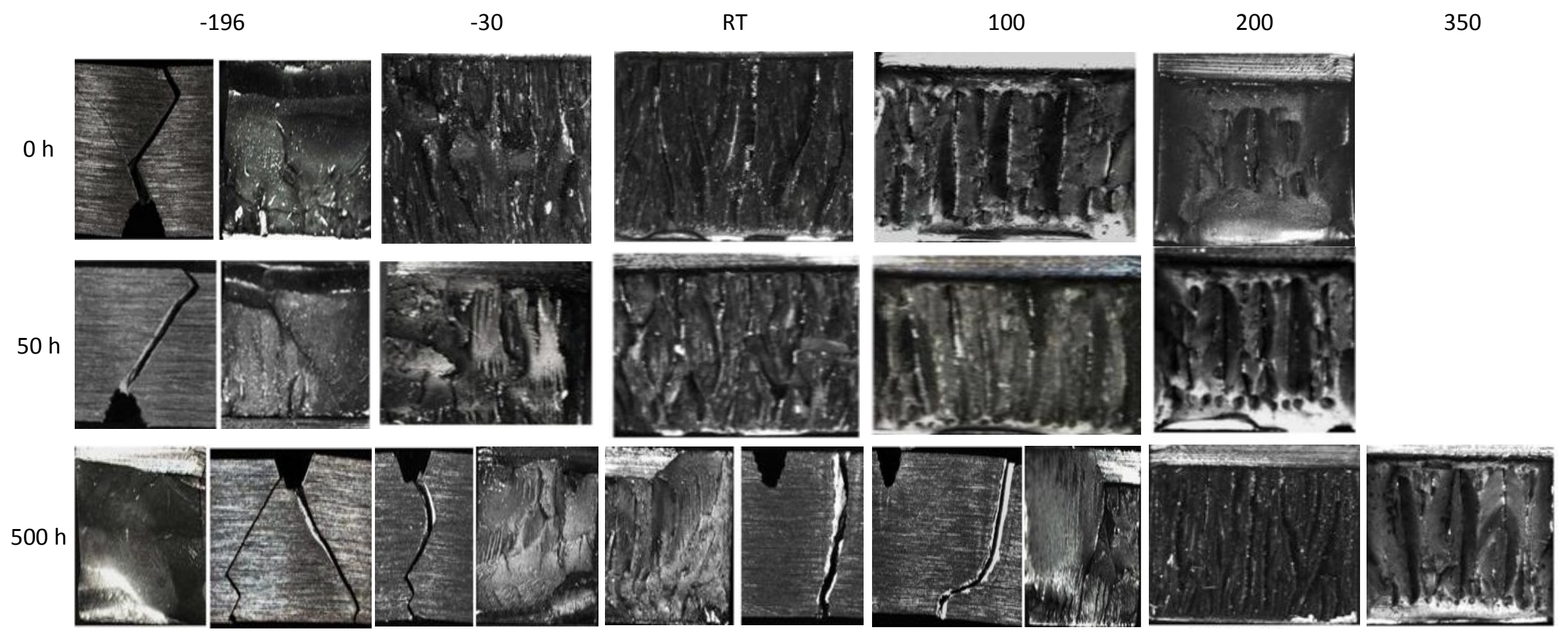

Figure 9. Fractography of LT samples aged at $475^{\circ} \mathrm{C}$ for different times and tested at different temperatures. 


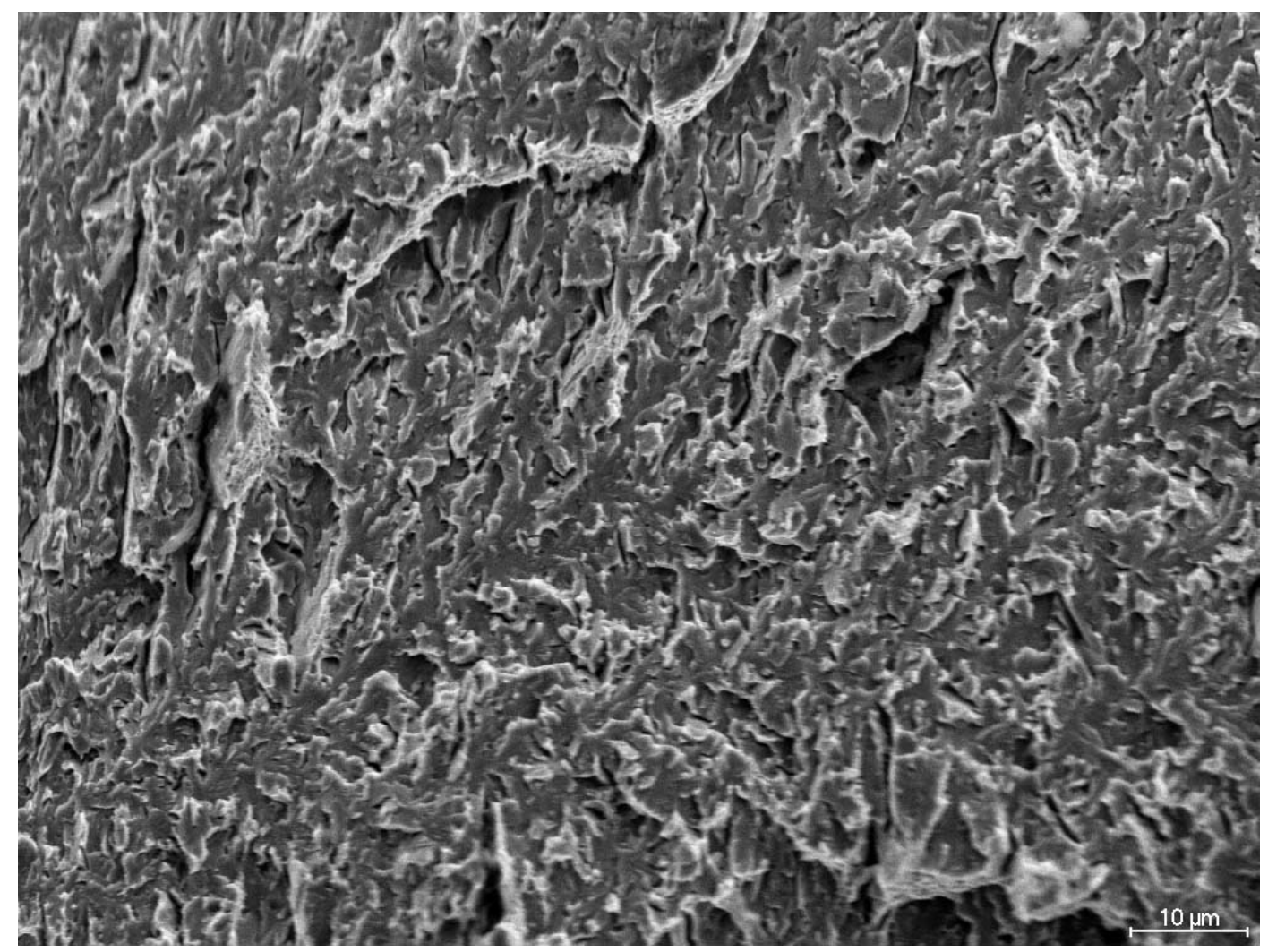

Figure 10. SEM image showing quasi-cleavage fracture in LT specimen aged for $500 \mathrm{~h}$ and tested at -80 으. 

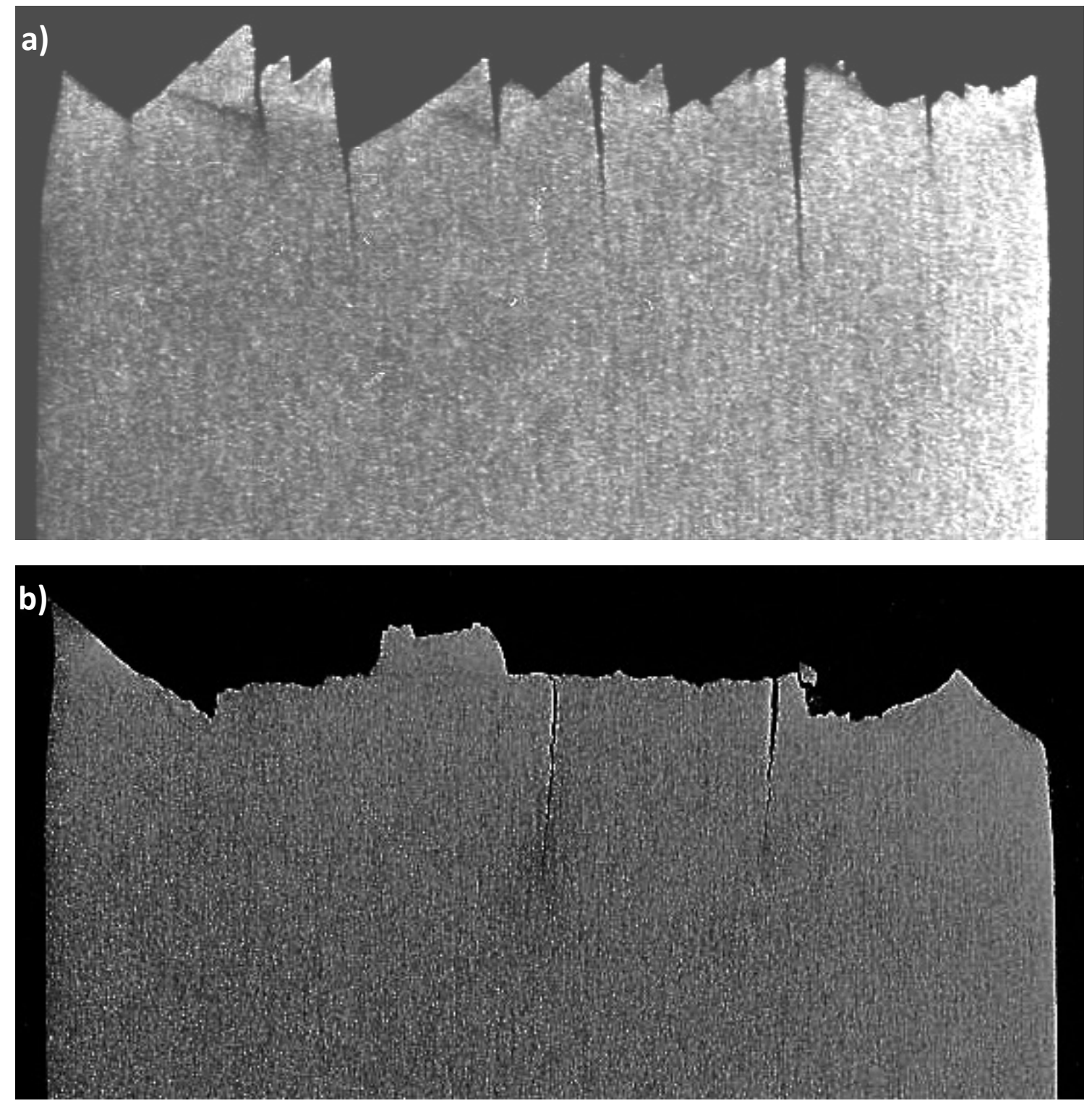

Figure 11. Fracture morphology of (a) LT sample aged for $50 \mathrm{~h}$ and tested at RT and (b) aged for $500 \mathrm{~h}$ and tested at $350^{\circ} \mathrm{C}$. Details of parallel delaminations are shown. 

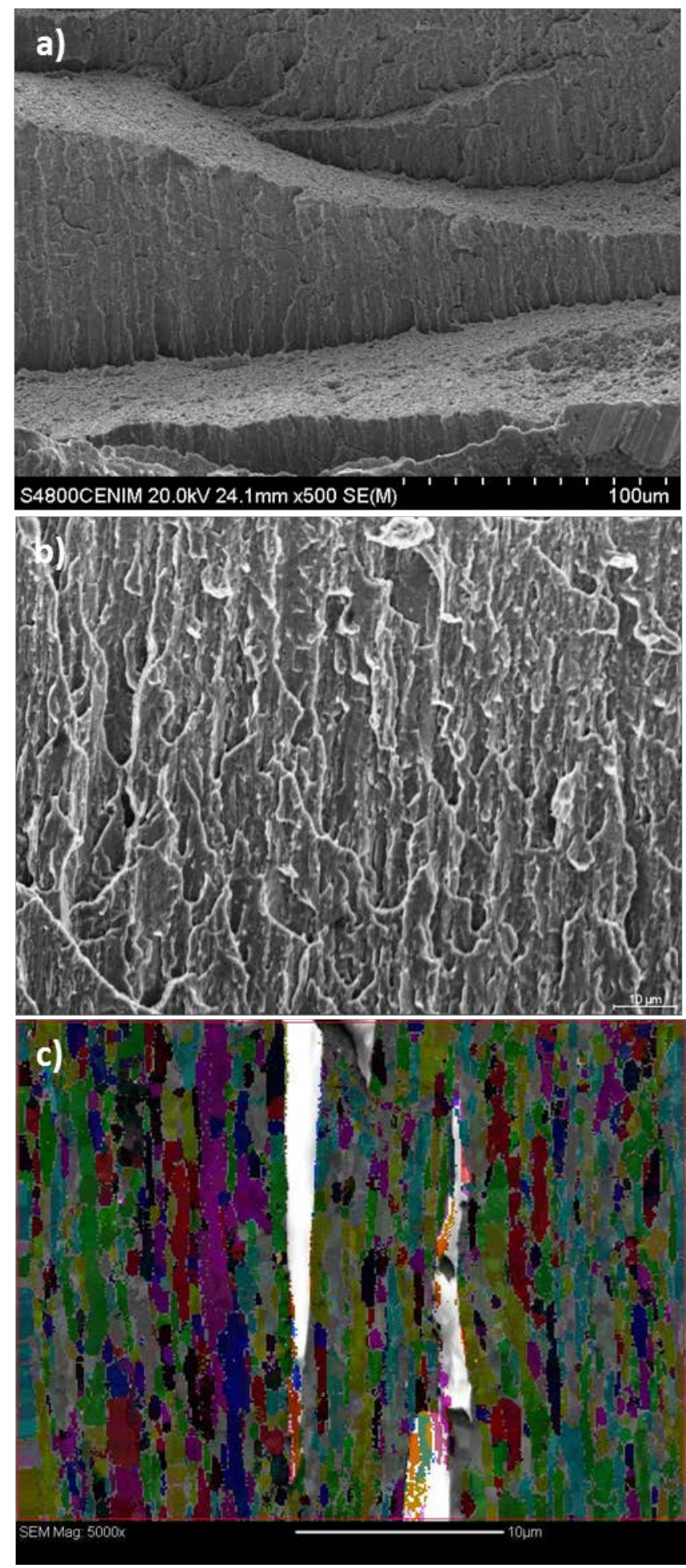

Figure 12. SEM images of LT specimen of the as-received material tested at RT. a) Low magnification SEM image showing the delaminations, b) SEM image showing the surface of delamination, and c) orientation map along RD on cross sectional plane parallel to tube surface. 
a)

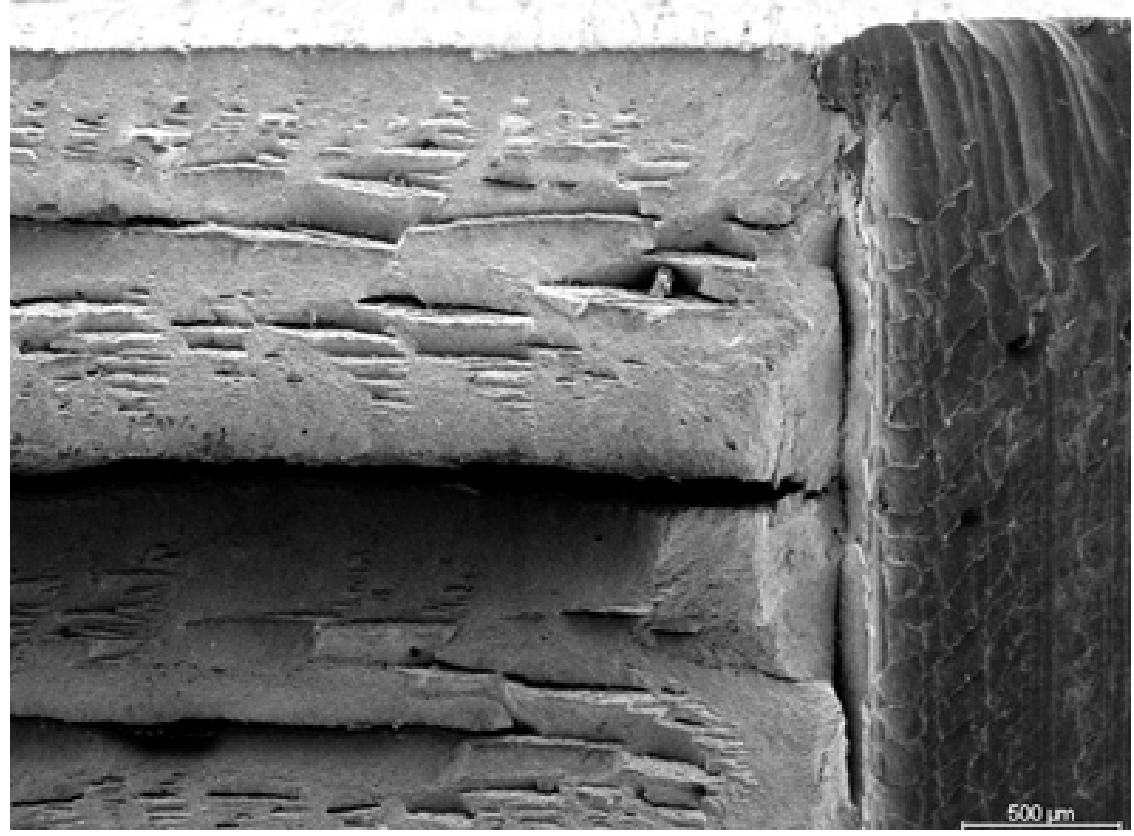

b)

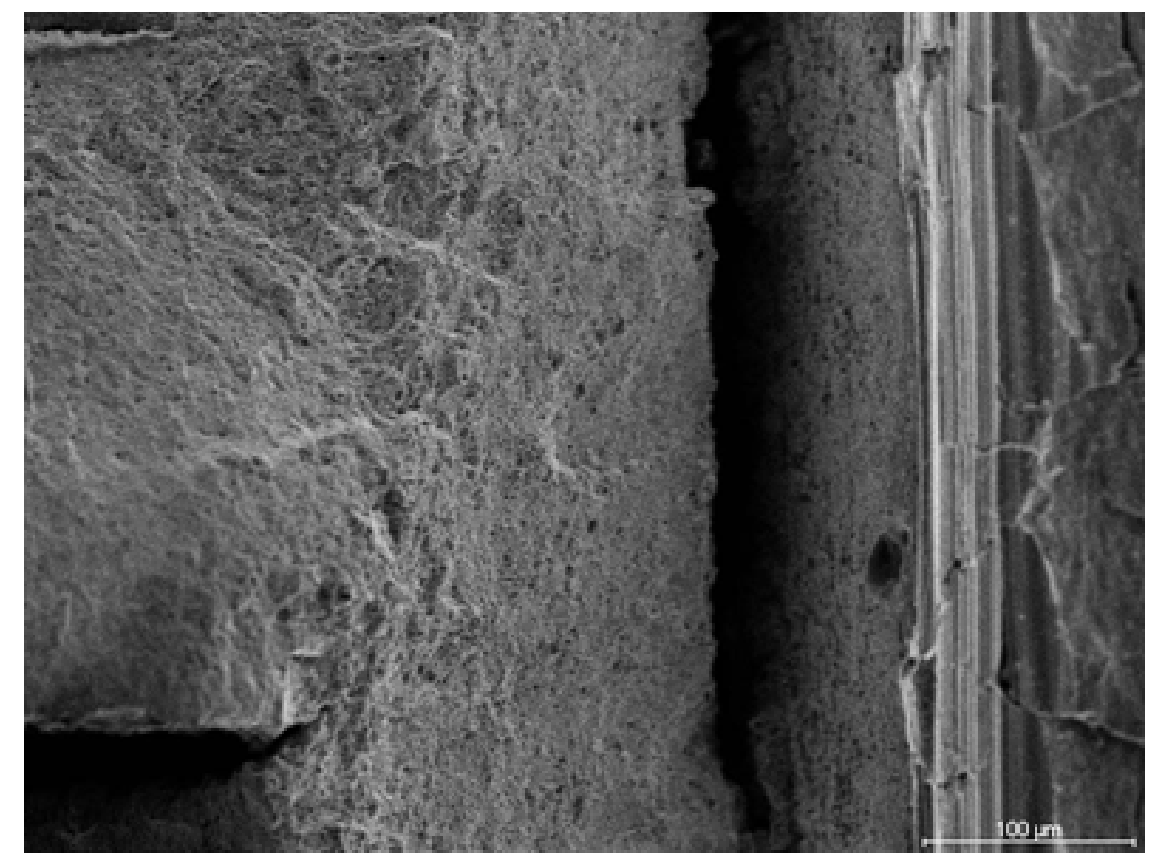

Figure 13. Low magnification SEM images showing (a) ductile delamination orthogonal to the main fracture and containing the notch front of LT specimen aged for $50 \mathrm{~h}$ and tested at RT, and (b) detail of main fracture plane. 
$-196$

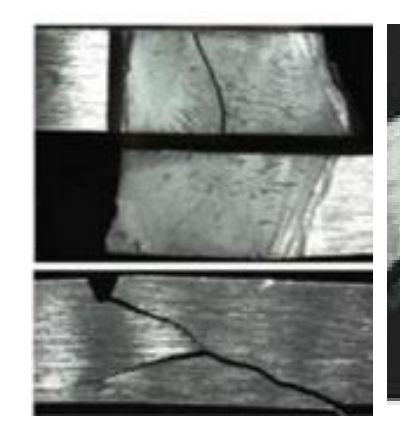

$50 \mathrm{~h}$
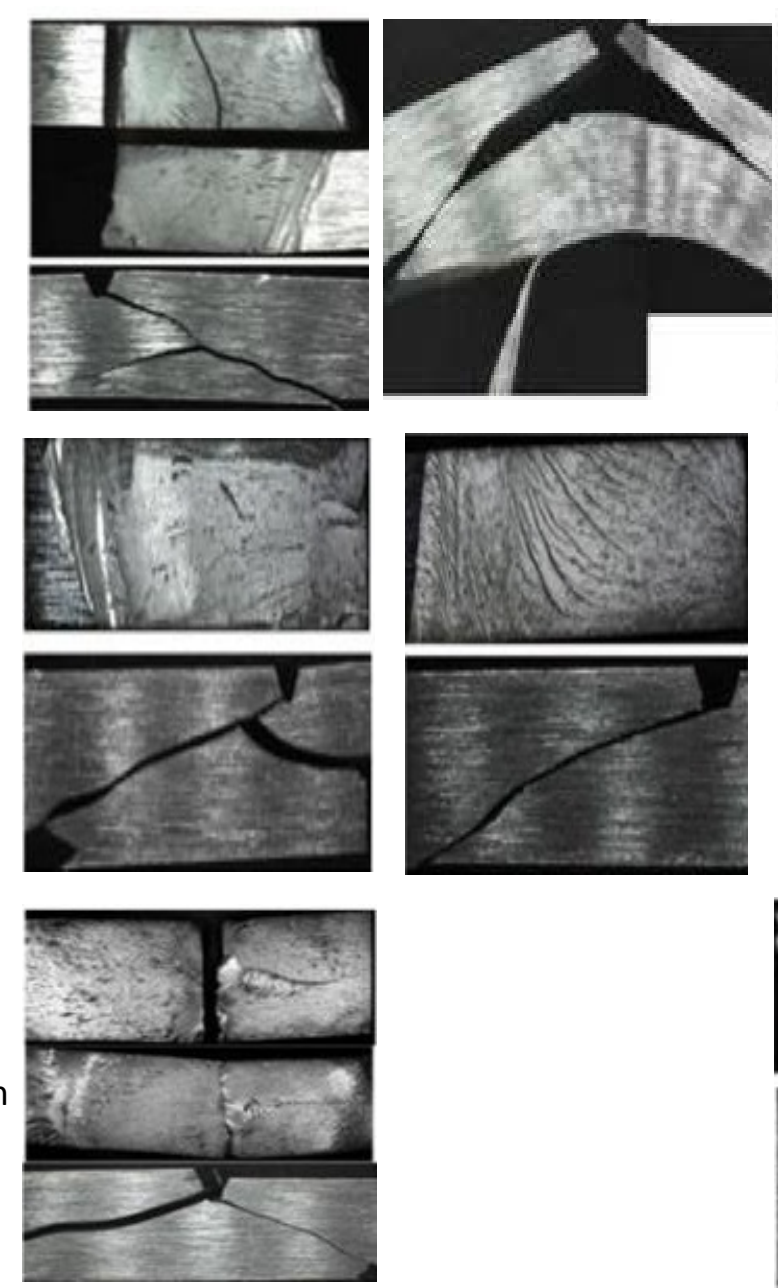

RT
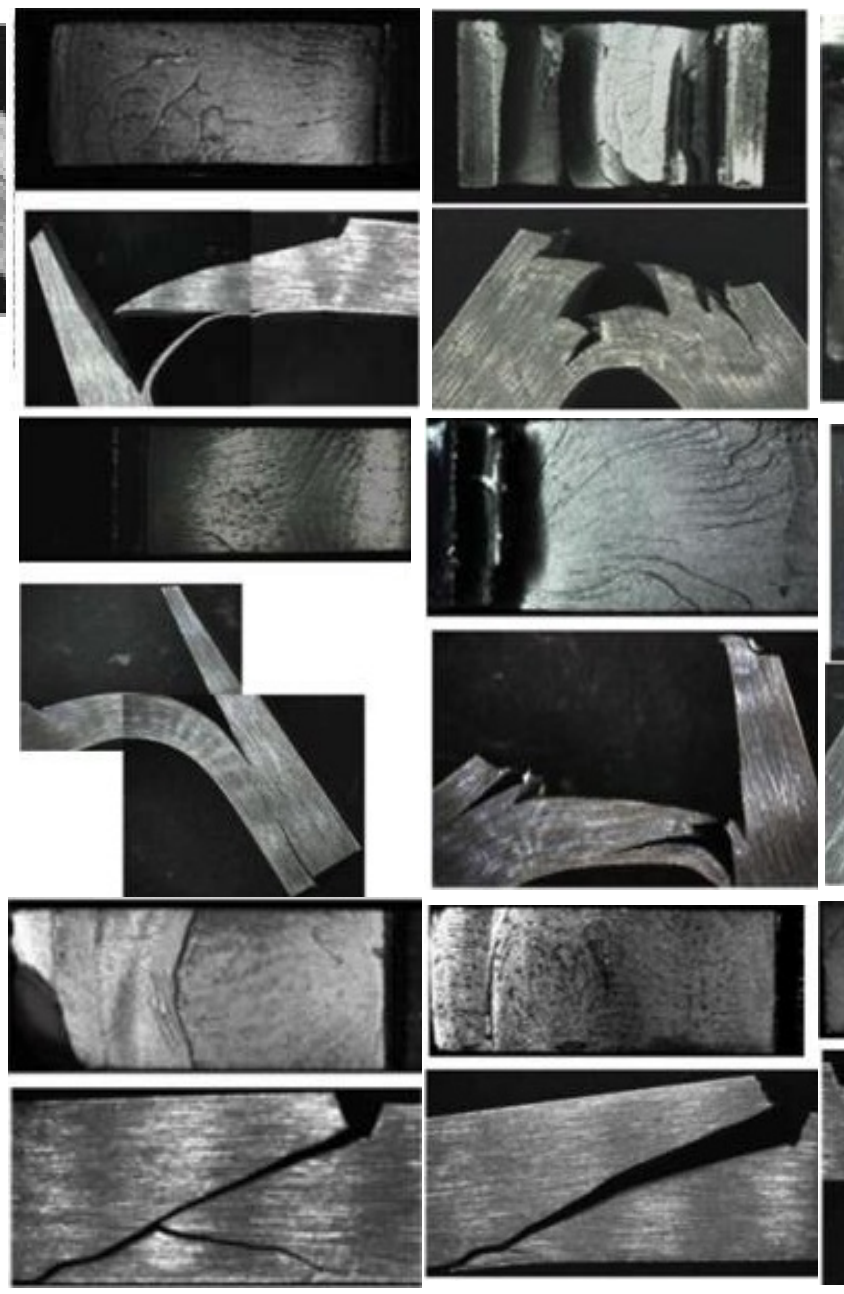

100
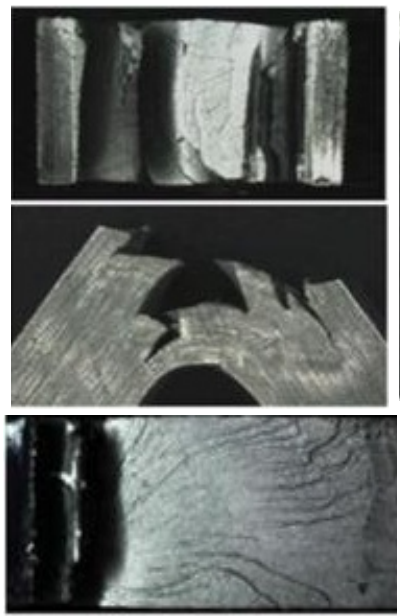

200

350
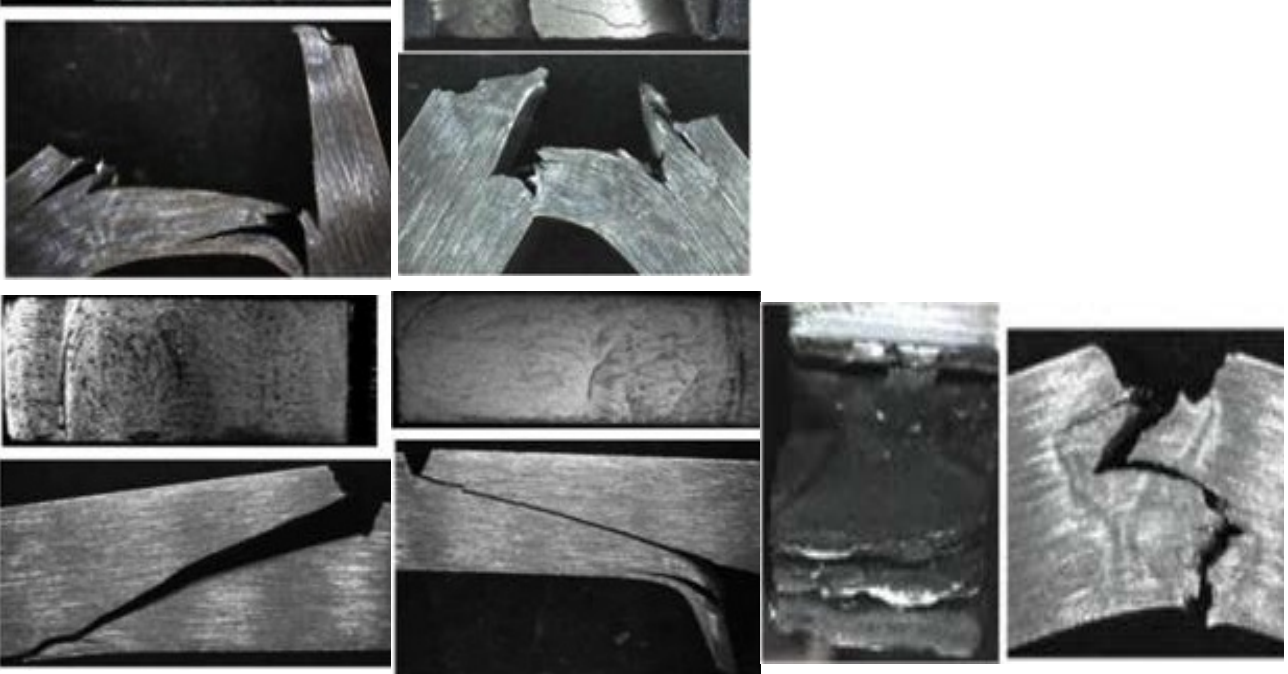

Figure 14. Fractography of LS specimens aged at $475^{\circ} \mathrm{C}$ for different times and tested at different temperatures. 

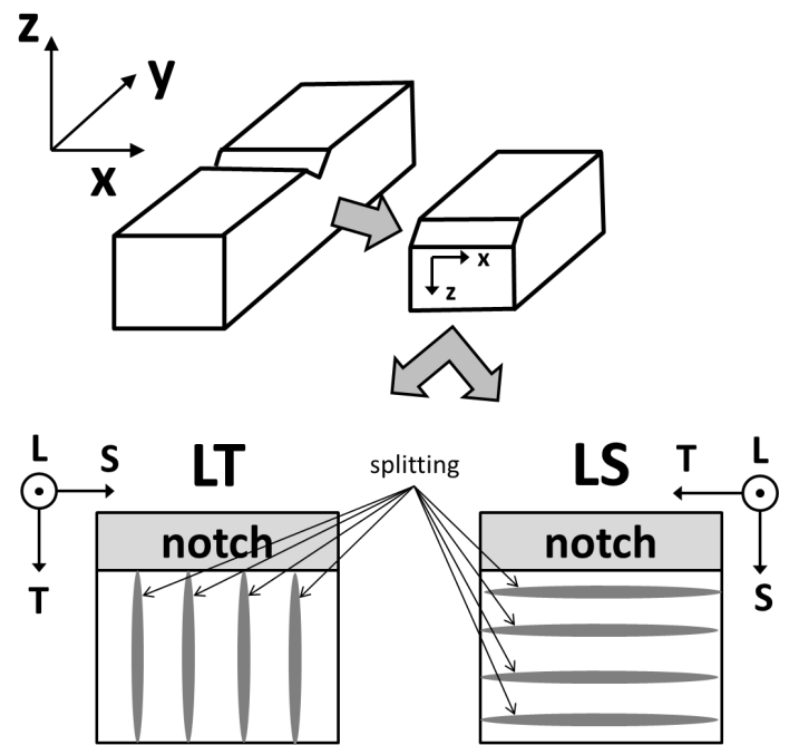

Figure 15. Schematic illustration showing laminate splitting geometries found in LT and LS samples tested according with Cartesian $x, y, z$ and L,T,S reference systems. (After Kimura et al. [34]). 